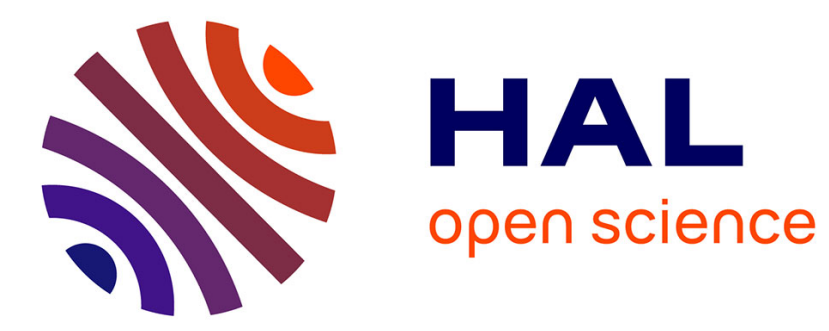

\title{
Optimal plate spacing for mixed convection from an array of vertical isothermal plates
}

H. Sun, R. Li, Eric Chénier, Guy Lauriat, J. Padet

\section{To cite this version:}

H. Sun, R. Li, Eric Chénier, Guy Lauriat, J. Padet. Optimal plate spacing for mixed convection from an array of vertical isothermal plates. International Journal of Thermal Sciences, 2012, 55, pp.16-30. 10.1016/j.ijthermalsci.2011.12.013 . hal-00692607

\section{HAL Id: hal-00692607 https://hal.science/hal-00692607}

Submitted on 3 Jun 2017

HAL is a multi-disciplinary open access archive for the deposit and dissemination of scientific research documents, whether they are published or not. The documents may come from teaching and research institutions in France or abroad, or from public or private research centers.
L'archive ouverte pluridisciplinaire HAL, est destinée au dépôt et à la diffusion de documents scientifiques de niveau recherche, publiés ou non, émanant des établissements d'enseignement et de recherche français ou étrangers, des laboratoires publics ou privés. 


\title{
Optimal plate spacing for mixed convection from an array of vertical isothermal plates
}

\author{
H. Sun ${ }^{\mathrm{a}}$, R. Li ${ }^{\mathrm{a}}$, E. Chénier ${ }^{\mathrm{a}}$, G. Lauriat ${ }^{\mathrm{a}, *}$, J. Padet $^{\mathrm{b}}$ \\ ${ }^{a}$ Université Paris-Est, Laboratoire Modélisation et Simulation Multi Echelle, UMR-CNRS 8208, \\ 5 Boulevard Descartes,77454 Marne-la-Vallée Cedex 2, France \\ ${ }^{b}$ Université de Reims Champagne-Ardenne, GRESPI EA 4301, Moulin de la Housse, \\ 51687 Reims Cedex 2, France
}

\begin{abstract}
Numerical simulations of mixed convection of air between vertical isothermal surfaces were conducted in order to determine the optimum spacing corresponding to the peak heat flux transferred from an array of isothermal, parallel plates cooled by mixed convection. Comparisons between approximate analytical solutions for natural and forced convection are first discussed. It is shown that the agreement is fairly good. From the computations carried out for aiding mixed convection by assuming a pressure drop at the outlet section rather than a constant flow rate, it is numerically predicted that the optimum spacing is smaller than those for pure natural or pure forced convection. This spacing is determined according to the pressure drop. As a sample, we considered an array of $10 \mathrm{~cm}$-height, isothermal surfaces at temperature $T_{h}=340 \mathrm{~K}$ with air as the working fluid entering into the channels at $T_{0}=300 \mathrm{~K}$. The increases in heat flux corresponding to the optimal spacing are discussed for outlet pressure drops ranging from $-0.1 \mathrm{~Pa}$ to $-1 \mathrm{~Pa}$. Such a range covers the entire mixed convection regime for this specific application.
\end{abstract}

Keywords: Mixed convection, vertical channels, optimal spacing, numerical simulations

\footnotetext{
*Corresponding author

Email addresses: Hua.Sun@univ-paris-est.fr (H. Sun), Ru.Li@univ-paris-est.fr (R. Li), Eric.Chenier@univ-paris-est.fr (E. Chénier), Guy.Lauriat@univ-paris-est.fr (G. Lauriat), Jacques.Padet@univ-reims.fr (J. Padet)
} 


\section{Nomenclature}

$a$

A

$B e$

$c_{p}$

$\overline{\bar{d}}$

D

$D_{h}$

$\mathrm{Fr}$

$g$

$G r_{D}$

$G_{v}$

$h$

H

$k$

$L$

$\dot{m}$

$n$

$\overline{N u}_{2 w}$

$\overline{N u}_{e n}$

$n_{x}, n_{z}$

$p$

$p_{m}$

$p_{s}$

$p^{*}$

$\operatorname{Pr}$

$Q$

$Q_{a}, Q_{b}$ thermal diffusivity $\left[m^{2} s^{-1}\right]$

aspect ratio, $A=H / D$

pressure difference number, $B e=\Delta p H^{2} / a_{o} \mu_{0}$

specific heat $\left[J \mathrm{~K}^{-1} \mathrm{~kg}^{-1}\right]$

deformation velocity tensor $\left[s^{-1}\right]$

plate spacing $[\mathrm{m}]$

hydraulic diameter, $D_{h}=2 D \quad[\mathrm{~m}]$

Froude number, $\mathrm{Fr}=w_{0}^{2} / g D_{h}$

gravitational acceleration $\left[m s^{-2}\right]$

Grashof number based on $\left.D, G r_{D}=g \beta_{0} \Delta T D^{3} / \nu_{0}^{2}\right)$

volumetric flow rate, $G_{v}=w_{0} S_{c}\left[m^{3} s^{-1}\right]$

heat transfer coefficient $\left[W m^{-2} K^{-1}\right]$

channel height $[m]$

thermal conductivity $\left[W m^{-1} K^{-1}\right]$

channel length in the direction perpendicular to Fig.1 $[m]$

mass flow rate $\left[k g ~ s^{-1}\right]$

number of channel

mean Nusselt number based on the wall heat fluxes

mean Nusselt number based on the enthalpy flux

numbers of grid points in $x$ - and $z$-directions

pressure $[P a]$

motion pressure $[P a]$

pressure at the outlet section $[\mathrm{Pa}]$

dimensionless pressure, $P=p /\left(\rho_{0} w_{0}^{2}\right)$

Prandtl number, $\operatorname{Pr}=\nu_{0} / a_{0}$

heat flux, $[W]$

analytical expressions for the heat flux, $[W]$ 
$Q_{2 w}$

$Q_{e n}$

$Q_{\text {cond }}$

$R a_{H}$

Re

Ri

$S_{c}$

$S_{T}$

$t$

T

$u, w$

$v_{r e f}$

$\mathcal{W}_{m}$

$x, z$

\section{Greeks}

$\alpha$

$\beta$

$\Delta T$

$\Delta p$

$\eta$

$\eta_{b}$

$\nu$

$\rho$

$\theta$

$\tau$

\section{Subscripts}

$a, b$ convective heat flux along the two vertical channel walls (Eq. 13), $[W]$ enthalpy heat flux (Eq. 14), [W]

axial difusion flux (Eq. 16), $[W]$

Rayleigh number based on $H, R a_{H}=g \beta \Delta T H^{3} / a_{0} \nu_{0}$

Reynolds number based on $D_{h}, R e=w_{0} D_{h} / \nu_{0}$

Richardson number, $R i=G r / R e^{2}$

area of the channel cross section, $S_{c}=D L\left[m^{2}\right]$

area of the overall heated surfaces, $S_{T}=2 n(H L)\left[m^{2}\right]$

time $[s]$

temperature $[K]$

velocity components $\left[\mathrm{m} \mathrm{s}^{-1}\right]$

reference velocity for natural convection, $v_{r e f}=\nu_{0} / D_{h} \quad\left[\begin{array}{ll}m s^{-1}\end{array}\right]$

pumping power $[W]$

coordinates $[m]$

order of consistency of the numerical scheme

thermal coefficient of volumetric expansion, $\beta=1 / T_{0}\left[K^{-1}\right]$

temperature difference, $\Delta T=\left(T_{h}-T_{0}\right)[K]$

pressure difference, $\Delta p=-\frac{1}{2} \rho_{0} \bar{w}^{2}-p_{s}[P a]$

efficiency (Eq. 44)

mixed convection group [36], $\left(R a_{H} / B e\right)^{1 / 4}$

kinematic viscosity $\left[\mathrm{m}^{2} \mathrm{~s}^{-1}\right]$

density $\left[\mathrm{kg} \mathrm{m}^{-3}\right]$

dimensionless temperature ratio, $\theta=\left(T-T_{0}\right) / \Delta T$

dimensionless time, $\tau=w_{0} t /\left(\operatorname{Re} D_{h}\right)$

analytical solutions 


$\begin{array}{ll}\text { cond } & \text { conduction } \\ \text { en } & \text { enthalpy } \\ h & \text { hot wall } \\ H & \text { quantity based on channel height } \\ n c & \text { natural convection } \\ \text { opt } & \text { optimum } \\ w & \text { wall } \\ 0 & \text { inlet section } \\ 2 w & \text { two walls }\end{array}$

\section{Superscripts}

$\begin{array}{ll}- & \text { averaged quantity } \\ * & \text { dimensionless quantity }\end{array}$




\section{Introduction}

Mixed convection occurs when both natural convection and forced convection heat transfer mechanisms interact. In vertical and inclined parallel-plate channels the bulk flow can be either upward or downward. The thermal and/or solutal buoyancy forces may be either assisting or opposing the forced flow according to the forced flow direction relative to gravity, and depending on the thermal and/or solutal conditions at both walls. The four important parameters are the channel aspect ratio, $A=H / D$, the Reynolds, Grashof and Prandtl numbers, Re, $G r$ and $P r$, respectively. The relative contributions of forced and natural convection effects are often discussed in term of the Richardson number, $R i=G r / R e^{2}$, or in term of $R i R e=G r / R e$. It should be noted here that the choice of the appropriate length scale for the buoyancy term (i.e. the length in the Grashof number) is not obvious while it should be the hydraulic diameter for the Reynolds number.

In the last three decades, mixed convection through parallel-plate channels and in ducts with various cross-sections has been extensively studied both for vertical and inclined configurations. However, reference results for mixed convection are relatively sparse in comparison with those for forced or natural convection flows in ducts. That is due to the large increase in the complexity and numbers of possible flow configurations occurring in practical applications: cooling of electronic equipment, solar energy collectors, compact heat exchangers and many others [1].

Most of the theoretical studies on laminar mixed convection in vertical, parallel-plate channels were for thermal conditions of uniform wall heat fluxes or uniform wall temperatures, the heating of the two walls being either identical or asymmetric. Analytical methods for fully developed flows were first derived by Aung and Worku [2-4]. This problem was revisited recently by Padet et al. [5-7] who determined relevant criteria for the transitions from natural to mixed convection and from mixed to forced convection. A combined perturbation and similarity approach was used by Yao [8] for solving the governing equations 
in the entry region for conditions of constant wall temperature and constant wall heat flux. Purely numerical solutions were obtained by Cheng et al. [9] who suggested modifications to the parabolic model (based on negligible streamwise diffusion terms in comparison with spanwise diffusion terms) and, a new algorithm for the analysis of buoyancy-induced flow reversal within vertical channels was introduced. Numerical solutions based on a fully elliptic formulation are only few. To our best knowledge, the first numerical study on mixed convection based on the full elliptic formulation was carried out by Jeng et al. [10] who showed the limitations of the parabolic model for low Reynolds number flows. Recently, flow reversal and flow recirculations were anew considered in details by Yang et al. [11] and by Desrayaud and Lauriat [12]. Only few numerical studies were conducted by using the elliptic formulation. The reason is that the writing of appropriate boundary conditions at the inlet and outlet sections is difficult to handle: it is the mathematical backbone of such approaches. The main interest in considering an elliptic formulation is that the axial conduction may be accounted for, which is of importance for low mass flow rate.

In this work, we are considering only mixed convection with buoyancy and pressure forces acting in the same direction: this case is generally termed as "assisting mixed convection". The first question to be raised is: which force assists the other? Most papers published in the current literature considers that natural convection assists forced convection, i.e. the flow rate is fixed and the effect of natural convection on the heat transfer rate is examined. We are solving the problem from a different viewpoint: forced convection generated by an additional pressure difference is aiding natural convection, as it is mostly the case for the cooling of electronic equipments or in the case of severe nuclear accident.

Amongst the difficulties underlying a general description of thermal mixed convection (the thermosolutal case [13-15] being out the scope of this work) are the occurrences of flow reversal and flow recirculations, the origins of which are fully different although there exists some confusion into the literature. On one hand, Aung and Worku [2] analytically demonstrated that flow reversal is impossible in the case of fully developed flow for sym- 
metrically heated channels at constant temperature. On the other hand, Desrayaud and Lauriat [12] showed numerically the occurrence of flow recirculations in the entrance region for the constant temperature case at relatively low Reynolds number. Linear stability analysis of laminar mixed convection in a vertical channel with constant heat flux imposed on the walls has been investigated by Chen and Chung [16]. They demonstrated that the fully developed flow is highly unstable, the critical Grashof number being strongly dependent on the Reynolds and Prandtl numbers. Non-linear local analysis [17] gave results in good agreement with those of Chen and Chung [16].

Flow reversals in vertical parallel-plate channels and in circular pipe have been quite extensively studied, both for developing and fully developed flows, experimentally as well as theoretically. The experimental works performed by Morton et al. [18] and Ingham et al. [19] for mixed-convection water flows in vertical pipes and relatively small Reynolds numbers have clearly shown the occurrence of flow reversal. Less experiments were devoted to parallel-plate channels. Flow reversal and its structure have been visualized by Gau and coworkers [20-22] for both assisted and opposed convection. Its occurrence originates from asymmetric heating conditions. Flow reversal can be easily predicted, just by using the simplest one-dimensional form of the governing equations $[2,7]$.

Flow recirculations are caused by an imposed flow rate and are predicted in the entrance section experimentally [23] as well as numerically when using an elliptical formulation [12]. The existence of a flow recirculation bubble is caused by increases in upstream velocities close to the heated walls. This increases is due the decrease in density in conjunction with the largest gravitational force that produces acceleration of the fluid in regions next to the walls where maximums of axial velocities are observed. To satisfy mass conservation, fluid is drawn downward from the centerline region when the flow rate is kept fixed, independently of the magnitude of the buoyancy force. These recirculations are thus directly linked to the inlet flow boundary conditions. 
As depicted above, a general study of mixed convection is beyond the scope of this paper. Therefore, we are just concentrating on the optimal spacing between isothermal plates arranged in an array and cooled by mixed convection. The optimal spacing for the cooling of an array of heated surfaces by natural or by forced convection is a problem that has attracted many experimental and numerical studies since the famous work by Elenbass [24]. This spacing corresponds to the peak heat flux that can be transferred by providing the surface of $n$ perfectly conducting fins.

When the parallel plates are cooled by natural convection, Bar-Cohen and Rohsenow [25] have demonstrated that the optimum spacing can be determined through an analytic optimization procedure based on maximizing the total heat transfer per unit volume. This method permits to find optimum spacings for various thermal boundary conditions at the walls. At the same time, Bejan [26], suggested that the optimal spacing can be determined by the intersection of two asymptotic solutions varying as $D^{-1}$ or $D^{2}$ (the foundation of the theory of the intersection of asymptotes, followed by the Constructal Theory [27],[28]). The first solution is based on the assumption that the thicknesses of boundary layers growing on vertical surfaces are much lower than $D / 2$ at the exit section $(z=H)$. On the other hand, the second solution assumes that the temperature of the coolant is uniformly equal to the temperature of the walls at the exit section. Later on, the optimum plate spacing for natural convection between heated vertical parallel plates was numerically analysed by Anand et al. [29] for channels subjected to uniform wall temperature and uniform heat flux heating conditions. Boundary layers approximations were introduced and calculations were conducted for various asymmetric heating parameters.

For forced convection Bejan and Scuibba [30] determined an optimal spacing, intersection of two asymptotic solutions in $D^{-2 / 3}$ when the distance between the walls is large enough and in $D^{2}$ when they are sufficiently close for the occurrence of a short thermal entry length. The optimal spacing of a stack of isothermal parallel boards cooled by forced convection was studied numerically and theoretically by Mereu et al. [31] according to the flow generation: 
fixed pressure drop $(\Delta p)$, mass flow rate $(\dot{m})$, or pumping power. For each of these cases, the optimal spacing and maximum overall thermal conductance of the stack were correlated in dimensionless form. It was shown that neither the constant $\Delta p$ model nor the constant $\dot{m}$ model is appropriate when the stack is cooled by a stream created by a fan or a pump. Campo [32] complemented the study conducted by Bejan and Scubbia [30] by proposing an order-of-magnitude analysis for channels with the plates heated with uniform heat fluxes. To this end, he introduced a new characteristic plate temperature based on the mean value of the axially variable temperature difference between plate and free-stream temperatures.

In many applications, especially for electronic components, cooling is performed by mixed convection in order to increase the efficiency of the fins while using low power fans. Laminar mixed convection between a series of parallel plates with planar heat sources was numerically investigated by Watson et al. [33] with conjugate conduction effects included. A fully elliptic formulation and extensions above the plates were considered for various plate-tofluid conductivity ratios. The thermodynamic optimization of cooling techniques for heat generating devices were examined in Bejan and Ledezma [34] and da Silva et Bejan [35] by considering five models for applications above and below room temperature. They showed, in particular, that the minimum fan power requirement for forced convection is minimum when the heat transfer area is optimized according to the relation $A=2 A_{f} / S t$, where $S t$ is the Stanton number and $A_{f}$ the flow cross-sectional area. For natural convection cooling, this optimization rule determines the maximum possible heat generation rate.

A single correlation for optimal spacing and maximal heat transfer rate density for mixed convection as well as for natural and forced convection in stacks of isothermal parallel plates was derived by Bello-Ochende and Bejan [36]. The starting point of the numerical study was the expressions of the optimal spacings for pure natural convection (Bejan, [26]) and pure forced convection generated by a pressure difference (Bejan and Sciubba [25]). Their results, extended to the Prandtl number range $[0.001,100]$ for natural and forced convection, re-inforced the argument that the role of the pressure drop number (or Bejan number) in 
forced convection is analogous to that of the Rayleigh number in natural convection. The authors claimed that the success of the universal correlation derived in their study is due to the systematic manner it was developed. We will compare our results against these correlations with air as working fluid in the Result section of the present paper.

We present in this paper numerical results obtained when the pressure and buoyancy forces act in the same direction. It is shown that an optimal spacing still exists for mixed convection but its value depends strongly on the pressure difference between the inlet and outlet sections.

The paper is organized as follows. In section 2, we present the problem formulation both in dimensional form and in dimensionless form for the specific case of a vertical flat-plate channel subjected to uniform and equal wall temperatures. The heat transfer characteristics are then discussed. Section 3 describes the numerical method used to solve the conservation equations and to satisfy the overall mass conservation. In section 4, results and discussion are presented successively for natural, forced and mixed convection. Concluding remarks are drawn in section 5 .

\section{Governing equations}

We consider two-dimensional, incompressible and laminar buoyancy-assisting flows inside vertical parallel-plate channels, as shown in Fig. 1. The fluid enters the channel stack of height $H$ at ambient temperature and traverses upward, being heated by the hot walls at uniform temperature $T_{h}$. The fully developed region may be eventually reached at the outlet $(z=H)$, after a development length mainly depending on the value of the plate spacing for the problem under consideration. On account of the maximum temperature difference invoked, it is assumed that all physical properties are constant except for the density in the buoyancy force in the vertical direction (Boussinesq approximation). The reference temperature has been taken as the inlet temperature, as in most of the solutions reported in the 
current literature. However, this choice remains an open question, as discussed by Barletta and Zanchini [37], especially for fully developed mixed-convection. By assuming also that the inlet and outlet boundary conditions are the same for each of the channels, we are thus considering the flow in only one channel (periodicity of the flow in the horizontal direction). Owing to the stability results by Chen and Chung [16], the governing equations are written in transient form in order to capture possible transitions to unsteady flows. With the $z$-axis pointing upwards and the origin of coordinates placed at the center of the inlet section, the conservation equations based on a fully elliptic model are

$$
\begin{gathered}
\frac{\partial u}{\partial x}+\frac{\partial w}{\partial z}=0 \\
\frac{\partial u}{\partial t}+u \frac{\partial u}{\partial x}+w \frac{\partial u}{\partial z}=-\frac{1}{\rho_{0}} \frac{\partial p}{\partial x}+\nu_{0}\left(\frac{\partial^{2} u}{\partial x^{2}}+\frac{\partial^{2} u}{\partial z^{2}}\right) \\
\frac{\partial w}{\partial t}+u \frac{\partial w}{\partial x}+w \frac{\partial w}{\partial z}=-\frac{1}{\rho_{0}} \frac{\partial\left(p+\rho_{o} g z\right)}{\partial z}+\nu_{0}\left(\frac{\partial^{2} w}{\partial x^{2}}+\frac{\partial^{2} w}{\partial z^{2}}\right)+g \beta_{0}\left(T-T_{0}\right) \\
\frac{\partial T}{\partial t}+u \frac{\partial T}{\partial x}+w \frac{\partial T}{\partial z}=a_{0}\left(\frac{\partial^{2} T}{\partial x^{2}}+\frac{\partial^{2} T}{\partial z^{2}}\right)
\end{gathered}
$$

\section{Boundary and initial conditions}

The boundary conditions are written:

$$
\begin{aligned}
& u=w=0, \quad T=T_{h} \text { at } x= \pm D / 2 \text { and for } 0<z<H \\
& u=0, \quad \frac{\partial w}{\partial z}=0, \quad p=-\rho_{0} w^{2} / 2, \quad T=T_{0} \text { for }-D / 2<x<D / 2 \text { and at } z=0 \\
& u=0, \quad \frac{\partial w}{\partial z}=0, \quad p+\rho_{0} g H=p_{s}, \quad \frac{\partial T}{\partial z}=0 \quad \text { for }-D / 2<x<D / 2 \text { and at } z=H
\end{aligned}
$$

The initial condition is a fluid at rest at uniform temperature $T_{0}$.

For natural convection $p_{s}=0$ while the buoyancy force is neglected in Eq. 3 (i. e. $g \beta_{0}(T-$ $\left.T_{0}\right)=0$ ) for forced convection.

For forced and mixed convection, a fall in hydrostatic pressure is prescribed at the outlet section (it could be as well an increase in pressure at the inlet section). Therefore, the prescribed boundary conditions are inlet temperature and outlet pressure, zero $z$-derivative for the vertical velocity component and zero horizontal velocity-component. It should be emphasized that these flow B.C. differ somehow from those used in most of previous works. 


\subsection{Dimensionless form}

Natural convection :

Three velocity scales $v_{r e f}$ are commonly used for natural convection: either $v_{r e f}=\nu_{0} / D$, or equivalently for gas flows $v_{r e f}=a_{0} / D$, or $v_{r e f}=(g \beta \Delta T H / P r)^{1 / 2}$ which appears to be more appropriate for boundary layer type flows.

Forced or mixed convection:

The velocity scale for forced convection with a prescribed volumetric flow rate is generally the inlet velocity, $w_{0}$. With the present model, this velocity scale is not a priori known. We set thus $v_{\text {ref }}=w_{0}=\left(-p_{s} / \rho_{0}\right)^{1 / 2}$, the maximal possible mean velocity corresponding to a non-viscous fluid.

As suggested in Jeng et al. [10], we introduce the following set of dimensionless quantities:

$$
x^{*}=\frac{x}{D_{h}}, \quad z^{*}=\frac{z}{D_{h} R e}, \quad \tau=\frac{w_{0} t}{D_{h} R e}, \quad u^{*}=\frac{u D_{h}}{\nu_{0}}, \quad w^{*}=\frac{w}{w_{0}}, \quad p^{*}=\frac{p}{\rho_{0} w_{0}^{2}}, \quad \theta=\frac{T-T_{0}}{T_{h}-T_{0}}
$$

where $D_{h}=2 D$ denotes the hydraulic diameter of the channel. The dimensionless governing equations are as follows

$$
\begin{gathered}
\frac{\partial u^{*}}{\partial x^{*}}+\frac{\partial w^{*}}{\partial z^{*}}=0 \\
\frac{\partial u^{*}}{\partial \tau}+u^{*} \frac{\partial u^{*}}{\partial x^{*}}+w^{*} \frac{\partial u^{*}}{\partial z^{*}}=-R e^{2} \frac{\partial p_{m}^{*}}{\partial x^{*}}+\frac{\partial^{2} u^{*}}{\partial x^{*^{2}}}+\frac{1}{R e^{2}} \frac{\partial^{2} u^{*}}{\partial z^{*^{2}}} \\
\frac{\partial w^{*}}{\partial \tau}+u^{*} \frac{\partial w^{*}}{\partial x^{*}}+w^{*} \frac{\partial w^{*}}{\partial z^{*}}=-\frac{\partial p_{m}^{*}}{\partial z^{*}}+\frac{\partial^{2} w^{*}}{\partial x^{*^{2}}}+\frac{1}{R e^{2}} \frac{\partial^{2} w^{*}}{\partial z^{* 2}}+\frac{G r}{8 R e} \theta \\
\frac{\partial \theta}{\partial \tau}+u^{*} \frac{\partial \theta}{\partial x^{*}}+w^{*} \frac{\partial \theta}{\partial z^{*}}=\frac{1}{P r}\left(\frac{\partial^{2} \theta}{\partial x^{* 2}}+\frac{1}{R e^{2}} \frac{\partial^{2} \theta}{\partial z^{* 2}}\right)
\end{gathered}
$$

where

$$
G r_{D}=\frac{g \beta_{0} D^{3} \Delta T}{\nu_{0}^{2}}, \quad \operatorname{Pr}=\frac{\nu_{0}}{a_{0}}, \quad R e=\frac{w_{0} D_{h}}{\nu_{0}}
$$

The dimensionless pressure $p_{m}^{*}$ stands for the motion pressure which can be calculated by the following equation

$$
p_{m}^{*}=p^{*}+\left(\frac{R e}{F r}\right) z^{*}
$$


where $\mathrm{Fr}=\frac{w_{0}^{2}}{g D_{h}}$ is the Froude number. If $w_{0} \rightarrow \infty, \operatorname{Re} / \mathrm{Fr} \rightarrow 0$, and the $x^{*}$-momentum equation shows that the motion pressure becomes constant within a channel cross section. When $R e>>1$, the axial diffusion terms in the momentum and energy equations becomes negligibly small in comparison with the transverse terms: a parabolic model is then relevant. For a fully established regime $\left(u^{*}=0, \theta=1\right)$, the only dimensionless parameter is thus $\mathrm{Gr} / \operatorname{Re}$ (see Aung and Worku [2, 4] or Padet et al. [5, 7]).

\section{Boundary and initial conditions:}

$$
\begin{aligned}
& u^{*}=w^{*}=0, \quad \theta=1 \text { at } x^{*}= \pm 1 / 4 \text { and for } 0<z^{*}<\frac{A}{R e} \\
& u^{*}=0, \quad \frac{\partial w^{*}}{\partial z^{*}}=0, \quad p_{m}^{*}=-w^{*^{2}} / 2, \quad \theta=0 \text { for }-1 / 4<x^{*}<1 / 4 \text { and at } z^{*}=0 \\
& u^{*}=0, \quad \frac{\partial w^{*}}{\partial z^{*}}=0, \quad p_{m}^{*}=p_{s}^{*}, \quad \frac{\partial \theta}{\partial z^{*}}=0 \text { for }-1 / 4<x^{*}<1 / 4 \text { and at } z^{*}=\frac{A}{R e}
\end{aligned}
$$

where $A=H / D_{h}$ is the height to spacing ratio of the channel.

$$
u^{*}=w^{*}=0, \quad \theta=0 \text { at } \tau=0 \quad \forall x^{*}, z^{*}
$$

The dimensionless forms of the governing equations and boundary conditions show that the problem solution depends on five dimensionless parameters: $A, F r, G r, \operatorname{Pr}$ and $R e$. The relative importance of the buoyancy force is characterized by the ratio $G r / 8 R e$. For pure natural convection, $w_{0}$ may be changed into $v_{r e f}=\nu_{0} / D_{h}$. Therefore, it is found that $R e=1$ and $\operatorname{Re} / F r=g D_{h}^{2} /\left(\nu_{0} / D_{h}\right)$.

\subsection{Heat transfer}

The total heat transfer rate released by two walls of depth $L$ and height $H$, denoted as $Q_{2 w}$, is calculated as follows:

$$
Q_{2 w}=\left.2 L k_{0} \int_{0}^{H} \frac{\partial T}{\partial x}\right|_{x=D / 2} d z=2 \bar{h}(L H)\left(T_{h}-T_{0}\right)
$$

where $\bar{h}$ is the mean heat transfer coefficient defined by right-hand side of equality (13). For natural or mixed convection, a mean Nusselt number expressed by $\overline{N u}_{2 w}=Q_{2 w} /\left[2(L H)\left(k_{0} \Delta T / D\right)\right]$ 
may be introduced [25]. The enthalpy flux removed from the two heated surfaces by the stream is

$$
Q_{e n}=\rho_{0} c_{p} S_{c}\left[(\overline{w T})_{H}-(\overline{w T})_{0}\right]
$$

where $(\overline{w T})_{z}$ is the cross-section averaged $(w T)$ over one channel of cross-section area $S_{c}=$ $D L$ defined as

$$
(\overline{w T})_{z}=\frac{1}{D} \int_{-D / 2}^{D / 2} w(x, z) T(x, z) d x
$$

By using again $2(L H)\left(k_{0} \Delta T / D\right)$ as a reference heat flux, we can define a Nusselt number $\overline{N u}_{e n}=Q_{e n} /\left[2(L H)\left(k_{0} \Delta T / D\right)\right]$.

It should be emphasized that $Q_{2 w}$ is always greater than $Q_{e n}$ because heat lost by axial diffusion at the channel inlet is not included into the definition of $Q_{e n}$. When the wall temperatures are kept fixed, $Q_{2 w}$ and $Q_{e n}$ merge provided that the Reynolds number is large enough for assuming that axial diffusion is negligibly small compared with $Q_{2 w}$ and $Q_{e n}$, as shown by Eqs. 8-10. The difference $Q_{c o n d}=Q_{2 w}-Q_{e n}$ yields the effect of axial diffusion which can be written according to Eq. 5 as

$Q_{\text {cond }}=\left.k_{0} L \int_{-D / 2}^{D / 2} \frac{\partial T}{\partial z}\right|_{z=0} d x=\left.2 k_{0} L \int_{0}^{H} \frac{\partial T}{\partial x}\right|_{x=D / 2} d z-\rho_{0} c_{p} L \int_{-D / 2}^{D / 2}\left[w(x, H) T(x, H)-w(x, 0) T_{0}\right] d x$

For negligible axial heat diffusion, equation 16 reads:

$$
\left.2 k_{0} L \int_{0}^{H} \frac{\partial T}{\partial x}\right|_{x=D / 2} d z=2 \bar{h}(H L)\left(T_{h}-T_{0}\right)=\rho_{0} c_{p} S_{c}\left[(\overline{w T})_{H}-(\overline{w T})_{0}\right]
$$

Such an approximation is one of the foundations introduced for establishing the analytical solutions reported in Ref. [27, 25, 30].

\section{Numerical method and validation}

\subsection{Numerical scheme}

The conservation equations were spatially discretized to second order by the finite volume method on a structured grid with variables co-localized at the center of the mesh. Centered approximations were used for the transport terms. A second-order Euler scheme 
was adopted for time derivatives at time $t=(n+1) \Delta t$, with an implicit treatment of the diffusion terms and an Adams-Bashforth extrapolation procedure for the transport terms. The velocity-pressure decoupling was handled by a projection method. The resolution of the Poisson problem with an appropriate source term $f, \nabla \cdot(\nabla \Phi)=f$, for calculating the pressure correction $\Phi=P^{n+1}-P^{n}$ is known to produce checkerboard oscillations when $\nabla \cdot($. and $\nabla($.$) are the collocated divergence and gradient respectively. To stabilize the pressure$ correction term, the Poisson equation has been substituted by $\widetilde{\nabla}^{2} \Phi=f-\left(\nabla \cdot(\nabla \widehat{\Phi})-\widetilde{\nabla}^{2} \widehat{\Phi}\right)$ where $\widetilde{\nabla}^{2} \Phi$ denotes the 5-points diffusion operator classically used on staggered meshes and $\widehat{\Phi}$ is an explicit approximation for $\Phi$ at time $t=(n+1) \Delta t$.

The solutions of Helmholtz problems for the components of velocity, temperature field and pressure correction, solution of the modified Poisson problem presented here-above, were obtained by the Bi-Conjugate Gradient Stabilized (BCGS) method, preconditioned by an incomplete LU decomposition. Owing to the axial symmetry of the flow, the problem was solved on the half-width of the channel. The faces of the mesh $x_{i}^{f}$ and $z_{k}^{f}$ are defined as follows:

$$
\begin{array}{cc}
\frac{x_{i}^{f}}{D / 2}=\frac{i}{n_{x}}-\frac{c_{x}}{2 \pi} \sin \left(\frac{i}{n_{x}} \pi\right), & 0 \leq i \leq n_{x} \\
\frac{z_{k}^{f}}{H}=\frac{\tanh \left(c_{z}\left(\frac{k}{n_{z}}-1\right)\right)}{\tanh \left(c_{z}\right)}+1, \quad 0 \leq k \leq n_{z}
\end{array}
$$

The coefficients $c_{x}$ and $c_{z}$ define the mesh refinements in the entrance region and along the isothermal wall. The time integration was performed with the Courant-Friedrich-Levy number kept fixed to $C F L=0.5$. The stationary solution is reached when $E^{n, n+1}<10^{-4}$ with

$$
E^{n, n+1}=\max _{X \in\{u, w, T\}}\left(\frac{\left\|X^{(n+1)}-X^{(n)}\right\|}{\left\|X^{(n+1)}\right\| \Delta t}\right)
$$

where $\|.\|_{2}$ is the discrete $L_{2}$-norm.

The asymptotic behavior of the numerical solution was investigated using a Richardson extrapolation on two or three sets of three meshes defined by $n_{x} \in\{10,20,40\}, n_{x} \in$ 
$\{20,40,80\}$ and $n_{x} \in\{40,80,160\}$ with, in all cases, $n_{z}=50 n_{x}$. This method leads to the extrapolated value of $f$ which is written:

$$
f_{\text {extrap }}=f_{n_{x}}+\frac{c_{n_{x}}}{\left(n_{x}\right)^{\alpha}}
$$

where $c_{n_{x}}$ is a coefficient depending on $n_{x}$ and $f_{n_{x}}$ is the numerical result on grid $n_{x} \times n_{z}$. For sufficiently fine meshes, the value of $\alpha$ must tend towards the order of consistency of the numerical scheme (i.e. $\alpha=2$ ), $f_{\text {extrap }}$ must then become independent of the mesh. The preliminary study carried out for validating the numerical procedure used the refinement coefficients $c_{x}=1$ and $c_{z}=1.5$.

\subsection{Heat flux convergence}

For small spacings, the transport of enthalpy may be negligibly small compared to thermal diffusion for natural convection or for forced convection when a small pressure difference is applied. It may therefore be assumed that heat transfer reduces to pure heat conduction in a rectangular $(x \times z)$-domain with $T( \pm D / 2, z)=T_{w}(z)$ in $0 \leq z \leq H, T(x, 0)=T_{0}$ at $z=0$ in $0<x<D / 2$ and, adiabatic conditions at $z=H$ in $0<x<D / 2$. By using the method of separation of variables for solving the 2D-heat conduction equation subjected to the above boundary conditions, the analytical solution writes :

$$
T(x, z)=T_{0}+\Delta T \sum_{n=0}^{\infty} \frac{E_{n}}{\cosh \left(\lambda_{n} \frac{D}{2}\right)} \cosh \left(\lambda_{n} x\right) \sin \left(\lambda_{n} z\right)
$$

where $\lambda_{n}=(2 n+1) \pi /(2 H)$. The coefficients of the series are as follows

$$
E_{n}=\frac{2}{H \Delta T} \int_{0}^{H}\left(T_{w}(z)-T_{0}\right) \sin \left(\lambda_{n} z\right) d z
$$

The conductive flux transfered from the side walls of depth $L$ at $x= \pm D / 2$ writes:

$$
Q_{\text {cond }}=\left.2 L \int_{0}^{H} k \frac{\partial T}{\partial x}\right|_{x=D / 2} d z=2 L k \Delta T \sum_{n=0}^{\infty} E_{n} \tanh \left(\lambda_{n} \frac{D}{2}\right)
$$

Owing to the adiabatic conditions at $x=0$ and at $z=H$, the conductive heat flux at surface $z=0$ equals $Q_{\text {cond }}$. It can be readily shown that the $Q_{c o n d}$-expression for $T_{w}(z)=T_{h}$, i.e.

$$
Q_{\text {cond }}=\frac{8 L k \Delta T}{\pi} \sum_{n=0}^{\infty} \frac{1}{2 n+1} \tanh \left[\frac{(2 n+1) \pi}{4}\left(\frac{D}{H}\right)\right]
$$


is a non-convergent series. Therefore, the numerical scheme cannot converge, as it can be seen from the results reported in Table 1 for $D=610^{-3} \mathrm{~m}, H=0.1 \mathrm{~m}, L=1 \mathrm{~m}$ and $\Delta T=40 K$. Despite the use of quite fine meshes, the order of consistency is found very different from $\alpha=2$ and the extrapolated values with the three sets of grids differ accordingly. This behavior shows the non-convergence of the numerical scheme for the wall heat fluxes. That is directly linked to the temperature discontinuity at $(x, z)=( \pm D / 2,0)$ into the continuous problem formulation. Such a non-convergent behavior obviously exists for convective heat transfer but it is almost hidden when considering large enough flow rates (or Re ) because axial diffusion becomes negligible.

For natural convection $\left(\operatorname{Pr}=0.71, R a_{H}=3.76 \times 10^{6}\right)$, the values of the average velocity $\bar{w}$, the enthalpy flux, $Q_{e n}$, and the convective flux, $Q_{2 w}$, reported in Table 2, show that Richardson extrapolation indicates a very good convergence for $\bar{w}$ and $Q_{e n}$ $\left(\bar{w}=0.14716 \mathrm{~m} / \mathrm{s}, Q_{e n}=40.246 \mathrm{~W}\right)$. However, $Q_{2 w}$ (and thus by conservation of fluxes, $\left.Q_{\text {cond }}=Q_{2 w}-Q_{e n}\right)$ gives no indication about spatial convergence. The question of illformulated boundary conditions has been investigated by Sadat and Salagnac [38] : the present discussion corroborates their very relevant study about the right methods for solving problems with singularities at the boundaries.

The conclusion is that the total heat transfer at the isothermal wall cannot be accurately calculated, except if axial conduction (refer to Eq. 16) is negligibly small: in that case $Q_{e n}$ may be considered as a relevant approximation of $Q_{2 w}$.

Possible attempts for solving this problem are the use of channel extensions as it was suggested in many previous numerical studies that we will briefly review in what follows for closely related flow configurations.

Naylor et al. [39] solved the full elliptic forms of the governing equations for pure natural convection using inlet flow boundary conditions based on the Jeffrey-Hamel flow in order to 
represent more realistically the entrance flow. Their solutions validated the inlet pressure approximation $\left(p=-\rho_{0} w^{2} / 2\right)$ commonly used in parabolic formulations. Their predictions of fluid separation at the channel inlet is not agreement with most of the elliptic solutions published so far, and appear to be caused by the shape of the extension. The optimization of plate separation of an open, vertical, parallel-plate channel that is cooled by natural convection of air with the plates symmetrically heated by uniform heat flux has been studied by Morrone et al. [40] by solving the full elliptic conservation equations in a I-shaped computational domain. Correlations for the dimensionless flow rate and optimal values of the spacing were derived and compared with the predictions of Bar-Cohen and Rohsenow [25] and Anand et al. [29]. The deviations at small values of the Grashof number were attributed to the importance of diffusive effects.

The problem of natural convection involving the buoyancy-driven interaction of the fluid motion in a semi-confined space (including horizontal channels open at both ends) with the flow in a large external space was extensively studied, both theoretically and numerically. This problem was reconsidered in a recent paper by Boetcher and Sparrow [41]. One of the two goals of this paper was to examine the impact of the size of the extended domain, boundary conditions on its surfaces, and the mesh density required to achieve high accuracy. As in Desrayaud and Lauriat [42], it was shown that the opening boundary condition must permit the fluid to enter and leave across a boundary in accordance with the dynamics of the situation, unlike it was suggested in most of the previous numerical studies. Khanafer and Vafai ([43]-[44]) showed that an accurate set of effective boundary conditions at the aperture plane for two-dimensional open-ended structures can be obtained from previous computations carried out when using an extended domain.

Natural convection of air in channel-chimney systems was studied experimentally [45], and numerically by using the stream function-vorticity approach and the control volume method by Manca et al. ([46]-[48]) for vertical channels heated symmetrically at uniform heat flux and with adiabatic extensions. Results obtained showed how and why the chimney effect worsens, and provide guidelines to determine if the channel-chimney system is in critical condition related to flow reattachment or separation. 
Closely related to what we are considering here is the paper by Bello-Ochende and Bejan [36]: the channel was fitted with upstream and downstream extensions whose lengths were selected based on accuracy tests. For the downstream extension domain, free slip and no penetration were specified at one side and zero stress at the other side in order to nullify the chimney effect. From our point of view, this procedure leads to unrealistic outflow fields for a periodic array of vertical channels.

Based on the work by Sadat and Salagnac [38], we are therefore suggesting an alternative approach to those based on channel extensions.

\subsection{Regularization of thermal conditions at the inlet corner}

Since the problem of convergence of the wall heat flux has been identified as linked to the temperature discontinuity in $(x, z)=( \pm D / 2,0)$, we have modified the temperature profile along the walls using the relationship:

$$
T( \pm D / 2, z)=T_{w}(z)=T_{0}+\left(T_{h}-T_{0}\right) \tanh (5000 z)
$$

Therefore the sum of the following series

$$
Q_{\text {cond }}=2 L \Delta T \sum_{n=0}^{\infty} E_{n} \tanh \left(\lambda_{n} D\right) \quad \text { with } \quad E_{n}=\frac{2}{H} \int_{0}^{H} \tanh (5000 z) \sin \left(\lambda_{n} z\right) d z
$$

converges to $Q_{\text {cond }}=-5.0136(W)$ for $D=610^{-3} m, H=0.1 m, L=1 m$ and $\Delta T=40 \mathrm{~K}$. It should be noted that the relative temperature difference $\left(T_{w}(z)-T_{0}\right) /\left(T_{h}-T_{0}\right)$ increases from $50 \%$ for $z=0.11 \mathrm{~mm}$ to $99 \%$ for $z=0.53 \mathrm{~mm}$ and up to $99.9 \%$ for $z=0.76 \mathrm{~mm}$. This regularization is thus very steep, and we expect it has little effect on the average velocity, and hence on the enthalpy heat flux.

Taking up the problem of heat conduction with the wall temperature corrected as $T_{w}(z)$, we see that the extrapolations (Tab. 3) give a value rounded to five significant digits for the heat flux equal to $Q_{\text {cond }}=-5.0138 \mathrm{~W}$. This regularization modifies very slightly the convective transfer as shown in Fig. 2 in which are drawn the enthalpy flux and convective flux on the isothermal wall for the problem of natural convection with or without the regularized temperature. By comparing the values of the average velocity and enthalpy flux 
with or without regularization we found that these values are identical to three significant digits : $\bar{w}=0.147 \mathrm{~m} / \mathrm{s}$ and $Q_{e n}=40.2 \mathrm{~W}$.

In conclusion, the regularization method adopted allows to calculate the solution with a very good accuracy and to study the axial conduction, dominant for low axial velocities (or $P e \ll 1)$.

The study of the mesh convergence of numerical solutions was made in the case of natural convection with a regularized temperature at the inlet corner. In addition to computations carried out for $D=6 \mathrm{~mm}$, we also considered the two spacings $D=1 \mathrm{~mm}$ and $D=10 \mathrm{~mm}$ which correspond to the smallest and largest value of $D$ considered in this study.

Once the reference solutions are established using the Richardson extrapolation method, we sought the irregular coarsest mesh which provides accurate numerical solutions to 3 significant digits, for all considered plate spacings. The retained mesh is composed of $40 \times 1000$ control volumes covering a half-channel, the mesh being finer along the isothermal wall and close to the entrance region by setting $c_{x}=1.64$ and $c_{z}=1.82$. The ratio between the smallest and largest length of a rectangular control volume is, for each direction of space, about 10. Rounded to 3 significant digits, we obtain for $L=1 \mathrm{~m}$ :

$Q_{2 w}=2.85 \mathrm{~W}, Q_{e n}=0.326 \mathrm{~W}$ and $\bar{w}=6.89 \cdot 10^{-3} \mathrm{~m} / \mathrm{s}$ for $D=1 \mathrm{~mm}$,

$Q_{2 w}=41.8 \mathrm{~W}, Q_{e n}=40.2 \mathrm{~W}$ and $\bar{w}=0.147 \mathrm{~m} / \mathrm{s}$ for $D=6 \mathrm{~mm}$,

$Q_{2 w}=57.0 \mathrm{~W}, Q_{e n}=55.6 \mathrm{~W}$ and $\bar{w}=0.172 \mathrm{~m} / \mathrm{s}$ for $D=10 \mathrm{~mm}$. 


\section{Results and discussions}

Although the conservation equations were presented in their transient form, only the steady-state solutions are discussed here. The height and depth of the isothermal plates at $T_{h}=340 \mathrm{~K}$ are set as $H=0.1 \mathrm{~m}$ and $L=1 \mathrm{~m}$, and the thermophysical properties of air evaluated at the inlet fluid temperature, $T_{0}=300 \mathrm{~K}$, are set as: $\rho_{0}=1.176 \mathrm{~kg} \cdot \mathrm{m}^{-3}, \mu_{0}=$ $1.8510^{-5}$ Pa.s, $c_{p, 0}=1006 \mathrm{~J} . \mathrm{kg}^{-1} \cdot \mathrm{K}^{-1}, k_{0}=0.0261 \mathrm{~W} . \mathrm{m}^{-1} \cdot \mathrm{K}^{-1}$. The two main parameters

of the problem are the plate spacing, $D$, and the outlet motion pressure, $p_{s}$. The plate spacing is varied from $D=10^{-3} m$ to $D=10^{-2} m\left(10 \leq A \leq 100,5.29 \leq G_{D} \leq 5.2910^{3}\right)$ and, $p_{s}$ is varied from $p_{s}=-0.1 P a$ to $p_{s}=-1 P a$.

\subsection{Natural convection}

For air flowing by natural convection in a channel of height $H=10 \mathrm{~cm}$ and subject to a temperature difference $\Delta T=40 \mathrm{~K}$, the Rayleigh number based on $H$ is $R a_{H}=G r_{D} \operatorname{Pr} A^{3}=$ $3.76 \times 10^{6}$. Two mean Nusselt numbers may be deduced from the overall heat fluxes defined by equations 13 and 14: $\overline{N u}_{2 w}=4.79 D Q_{2 w}$ or $\overline{N u}_{e n}=4.79 D Q_{e n}$.

The asymptotic heat transfer correlations reported in Bejan [27] for small or large spacings may be combined for deriving a $\overline{N u}$-correlation valid whatever the spacing is [25]. However, these predictions assume that the axial heat conduction is negligibly small despite that the temperature at the inlet section is kept fixed at the ambient temperature for all flow rates. The assumption of constant inlet temperature is also used in the present study (see Eq. 5). Nevertheless, the elliptic formulation allows comparisons between the total heat transfer rate released by the two walls and the change in the enthalpy flux between the inlet and outlet sections, denoted in dimensionless form as $\overline{N u}_{2 w}$ and $\overline{N u}_{e n}$ (Table 4).

In terms of the present dimensionless variables, the composite heat transfer correlation given by Bar-Cohen and Rohsenow [25] for symmetric, isothermal plates may be written as

$$
\overline{N u}_{a}=\frac{1}{A}\left[\frac{576 A^{6}}{R a_{H}^{2}}+\frac{2.873}{R a_{H}^{1 / 2}}\right]^{-1 / 2}
$$


The first term in Eq. 28 dominates for small spacings while the second term dominates for large spacings since it is based on boundary-layer type correlations. Equation 28 allows calculations of the wall heat fluxes provided that the axial thermal diffusion is negligibly small (i.e. $Q_{2 w} \approx Q_{e n}$ ) and, therefore, an approximate analytical expression for the mean flow velocity, $\bar{w}_{a}$, is obtained as:

$$
Q_{2 w, a}=\rho c_{p, 0}(L D) \bar{w}_{a} \Delta T=(2 L H) k_{0}\left(\frac{\Delta T}{D}\right) \overline{N u}_{a} \Rightarrow \bar{w}_{a}=2\left(\frac{a_{0}}{D}\right) A \overline{N u}_{a}
$$

It should be noted that Eq. 29 is valid if the outlet bulk temperature is equal, or very close, to that of the walls since it is assumed that $T_{b}(H)=T_{h}$ when deriving this equation.

Table 4 shows that the agreement between $\overline{N u}_{a}$ and $\overline{N u}_{e n}$ is fairly good for all spacings considered while large discrepancies between $\overline{N u}_{a}$ and $\overline{N u}_{2 w}$ are reported for $D<4 \mathrm{~mm}$ owing to the small flow rates. Figure 3 shows that the analytical and numerical predictions for $\bar{w}$ are in good agreement up to $D \approx 7 \mathrm{~mm}$. For larger spacings, the boundary layertype solution (Eq. 29) is inappropriate for predicting the flow rate because the outlet velocity profiles calculated numerically are fully different from those for two separate boundary layers : in that case, the temperature along the channel axis (i.e. $T(0, z))$ should be equal to the inlet temperature. From Fig. 4 showing the temperature profile at the outlet section for various spacings, it can be deduced that the axial temperature at the outlet section is much higher than the inlet temperature. On the other hand, the decreases in the relative importance of axial conduction when increasing the spacing leads to smaller differences between $\overline{N u}_{a}$ and $\overline{N u}_{2 w}$ (Table 4$)$.

\subsubsection{Optimal spacing : $D_{\text {opt }}$}

The optimal spacing $D_{\text {opt }}$ corresponds to the maximum heat flux that is possible to transfer between an ambient fluid flowing between $2 n$ isothermal surfaces $(n+1$ plates) forming a stack of $n$ channels of total width $W$ (Fig. 1). Such a spacing is just a compromise between overall heat transfer area, $S_{t}=2 n \times H \times L$, and heat transfer in each of the $n$ channels, $Q_{2 w}(D)$ or $Q_{e n}(D)$. The optimal spacing for natural convection may be approximately determined from the asymptotic analysis presented in Bejan [27] or by using the 
$\overline{N u}$-correlation by Bar-Cohen and Rohsenow [25]. As a result, the ratio $Q_{e n}(D) / D$ varies between a value close to zero (corresponding to a very small plate-spacing such as $\bar{w} \approx 0$ ) and the value for $D=W$, in between there exists an optimum spacing, $D=D_{\text {opt }}$, at which $Q_{e n}(D) / D$ reaches a maximum value.

$D_{\text {opt }}$ can be estimated from the intersection of two curves corresponding to asymptotic solutions [27] or by using the correlation proposed in [25]. The solution given in [27],[36] is $D_{\text {opt }} \cong 2.3 \mathrm{H} \times R a_{H}^{-1 / 4}$, i.e. $D_{\text {opt }} \cong 5.22 \mathrm{~mm}$ for the configuration considered here. The optimization procedure suggested by Bar-Cohen and Rohsenow [25] leads to $D_{\text {opt }}=2.714 \mathrm{H} \times R a_{H}^{-1 / 4}$, i.e. $D_{\text {opt }}=6.16 \mathrm{~mm}$.

Figure 5 shows the variation of $Q / D(W / m)$ as a function of $D, Q_{a} / D$ and $Q_{b} / D$ being calculated by using the following correlations [27]

$$
Q_{a} / D=\frac{k_{0} L \Delta T}{12} R a_{H} \frac{D^{2}}{H^{3}}=0.32710^{9} D^{2} \quad \text { and } \quad Q_{b} / D=\frac{2 k_{0} L \Delta T}{D} 0.517 R a_{H}^{1 / 4}=\frac{47.54}{D}
$$

In Fig. 5, $D_{\text {opt }}$ corresponds to the maximum value of $Q_{2 w} / D$. Figure 5 shows that $Q_{2 w} / D$ and $Q_{e n} / D$ differ significantly for $D<4 \mathrm{~mm}$. The reason is that $Q_{e n} / D$ systematically tends towards zero as $D \rightarrow 0$ because $\bar{w} \rightarrow 0$. On the other hand, $Q_{2 w}$ decreases less quickly than $D$ because the problem turns into a pure conductive heat transfer problem as depicted in section III. As a result $Q_{2 w} / D$ increases sharply as $D \rightarrow 0$ and tends towards $Q_{\text {cond }} / D$, the exact analytical solution for regularized hot-wall temperatures (Eq. 27). The difference $Q_{2 w} / D-Q_{e n} / D$ is thus the conductive heat flux lost by the fluid at the inlet section, as given by Eq. 16. This result raises obviously the problem of the classical choice of the temperature boundary condition at the inlet. Solving this question is out of the scope of the present study.

It can also be seen in Fig. 5 that the numerical solution for $Q_{e n} / D$ is in excellent agreement with the asymptotic prediction for small spacings, i.e. for low fluid velocities while it starts diverging from $Q_{a} / D$ when $D \geq 4 \mathrm{~mm}$. For large spacings, the numerical solution 
does not agree well with the asymptotic solution for boundary-layer type flows, as discussed previously (Fig. 4): the $Q_{b}$-solution (Eq. 30) is not an upper bound for the heat flux. On the other hand, the agreement with the Bar-Cohen and Rohsenow correlation [25] is much better, as displayed in Fig. 6. $Q_{c} / D$ is calculated as follows

$$
Q_{c} / D=(2 L H) k_{0}\left(\frac{\Delta T}{D^{2}}\right) \overline{N u}_{a} \Rightarrow Q_{c} / D=2.09\left[4.068 \times 10^{-17} D^{-5}+1.481 \times 10^{-3} D\right]^{-1 / 2}
$$

From the present numerical results, $D_{\text {opt }}$ is found to be $D_{\text {opt }}=6.52 \mathrm{~mm}$ or $D_{\text {opt }}=6.62 \mathrm{~mm}$ by considering either the maximum in $Q_{e n} / D$ or in $Q_{2 w} / D$. These values are in good agreement with the maximum of $Q_{c} / D$ located at $D_{\text {opt }}=6.16 \mathrm{~mm}$ [25]. Figure 7 shows axial velocity profiles and temperature distributions at various height of the channel for $D_{\text {opt }}=6.62 \mathrm{~mm}$. In that case, $Q_{2 w}=48.5 \mathrm{~W}$ while $Q_{b}=47.3 \mathrm{~W}$ (Eq. 30$)$ and $Q_{c}=47.04 \mathrm{~W}$ (Eq. 31). The discrepancies are therefore very small. However, Figure 7 shows that the velocity and temperature profiles are far to be like those for a boundary layer-type flow : they resemble more or less the profiles for an established channel flow.

Bello-Ochende and Bejan [36] suggested to take into account the Prandtl effect on $D_{\text {opt }}$ and maximum heat transfer density $Q_{\max } / D$, obtained by substituting $D$ by $D_{\text {opt }}$ in Eq. 30 , as

$$
D_{o p t} \cong 0.0104 A(\operatorname{Pr}) H R a_{H}^{-1 / 4} \quad \Longrightarrow \quad Q_{\max } / D_{o p t} \leq 0.028 B(\operatorname{Pr})\left(\frac{k_{0} \Delta T}{H}\right) R a_{H}^{1 / 2}
$$

where $A(P r)=\left[263^{0.52}+\left(2.83 P r^{0.667}\right)^{0.52}\right]^{1 / 0.52}$ and $B(P r)=\left[15.5^{-0.51}+\left(181 P r^{0.81}\right)^{-0.51}\right]^{-1 / 0.51}$. These correlations are assumed valid in the range $10^{5} \leq R a_{H} \leq 10^{7}$ and $10^{-3} \leq \operatorname{Pr} \leq 10^{2}$. The result for $\operatorname{Pr}=0.71$ and $R a_{H}=3.76 \times 10^{6}$ is reported on Fig. 5. As can be seen, there is a large discrepancy with the present results, both on $D_{\text {opt }}$ and $Q_{\max } / D_{\text {opt }}$ which stands much below our predictions.

\subsection{Forced convection}

The asymptotic analysis presented in Bejan et Sciubba [30] leads to the following results: - if the flow regime may be assumed dynamically and thermally established over the most 
part of the height of a vertical channel, the enthalpy flux may approximated as

$$
Q_{a} / D=\frac{D^{2}}{12 \nu_{0}}\left(\frac{\Delta p}{H}\right) c_{p, 0} \Delta T
$$

- on the other hand, the boundary layer limit approximation leads to

$$
Q_{b} / D=1.208 k_{0} \Delta T\left(\frac{(\operatorname{Pr} H \Delta p)^{1 / 3}}{\rho_{0}^{1 / 3} \nu_{0}^{2 / 3} D^{2 / 3}}\right)
$$

Equation 34 is based on the Blasius solution for forced flows over a flat plate and by assuming that the velocity along the channel axis, keeping a constant value, is created by a pressure difference $\Delta p$.

Based on these two limits, the optimum spacing results from the equality $Q_{a}=Q_{b}$. It can be readily shown that [30][36]

$$
D_{\text {opt }, a} \cong 2.726 H^{1 / 2}\left(\frac{a_{0} \mu_{0}}{\Delta p}\right)^{1 / 4} \cong 2.726 H B e^{-1 / 4}
$$

where $B e=\frac{\Delta p H^{2}}{a_{o} \mu_{0}}$ is the pressure difference number or Bejan number. With the present set of data, $D_{o p t, a}$ can be rewritten as $D_{\text {opt }, a} \cong 3.8810^{-3} \Delta p^{-1 / 4}$.

The order of magnitude of the maximum heat flux that corresponds to $D_{\text {opt }}$ is obtained by combining Eq. 33 and Eq. 35:

$$
Q_{\text {max }} \cong 0.62 D_{\text {opt }}\left(\frac{\rho_{0} \Delta p}{P r}\right)^{1 / 2} c_{p, 0} \Delta T=0.62 B e^{1 / 2} D_{\text {opt }}\left(\frac{k_{0} \Delta T}{H}\right)
$$

With the present set of data, $Q_{\max }$ can be rewritten as $Q_{\max } \cong 124.4 \Delta p^{1 / 4}$. Similarly to what has been done for natural convection, equations 35 and 36 were reformulated in [36] in order to correlate the Pr effect as

$$
D_{\text {opt }} \cong 0.0114 A(P r) H B e^{-1 / 4} \quad \text { and } \quad Q_{\max } / D_{o p t} \cong 0.035 B(\operatorname{Pr})\left(\frac{k_{0} \Delta T}{H}\right) B e^{1 / 2}
$$

where $A(P r)$ and $B(P r)$ are the same as for natural convection. 
It should be noted that equations 35 and 36 cannot be directly applied if the fluid flow is created by a pressure drop at the outlet section because the inlet pressure depends on the inlet velocity through the Bernoulli relationship. On other hand, it is straightforward to calculate $D_{o p t, a}$ and $Q_{o p t, a}$ if the inlet pressure is fixed while assuming $p_{s}=0$. With the model used in the present study, the mass flow rate, $\dot{m}=\rho_{0}(D L) \bar{w}$, as well as the inlet pressure, $p(x, 0)$, result from solving the conservation equations $(7)-(10)$ with the boundary conditions given by Eq. (11). Therefore, we applied Eq. 33 to Eq. 37 through calculations of the pressure difference as $\Delta p=\bar{p}(0)-p_{s}=-\frac{1}{2} \rho \bar{w}^{2}(0)-p_{s}$, where $\bar{w}$ depends on $p_{s}$ and $D$. The mean velocity for $D_{\text {opt }}$ and various $p_{s}$ is reported in Table 5 . It can be deduced that the Reynolds number based on the hydraulic diameter ranges within $171 \leq R e \leq 309$ when 0. $1 P a \leq\left|p_{s}\right| \leq 1 P a$.

The ratios $Q_{2 w} / D$ and $Q_{e n} / D$ are shown in Fig. 8a and $8 \mathrm{~b}$ for $p_{s}=-0.1 P a$ and $p_{s}=-1 P a$, the asymptotic solutions $Q_{a} / D$ and $Q_{b} / D$ being drawn in dashed lines. As can be seen, the agreement between the numerical solution (maximum of $Q_{2 w} / D$ ) and analytical solution (intersection of $Q_{a} / D$ and $Q_{b} / D$ ) for $D_{\text {opt }}$ is better than for natural convection. On the other hand, the optimal plate-spacing calculated using Eq. 37 [36] does not agree neither with our computations nor with Eq. 35.

Table 5 shows comparisons between the analytical (Eq. 35) and numerical values of $D_{\text {opt }}$ as a function of $p_{s}$ : the agreement is satisfactory. The analytical solution (Eq. 36) slightly overestimates the peak in $Q_{2 w} / D_{\text {opt }}$ as shown from comparisons between the last two lines of Table 5. Therefore, that can be assumed as a rather good approximation of the maximum of $Q_{2 w} / D$ (within 20\%) for the range of $p_{s}$ considered in the present study $\left(0.1 P a \leq\left|p_{s}\right| \leq 1 P a\right)$.

In Figs. $8 \mathrm{a}$ and 8b, the effect of axial conduction is exhibited through the discrepancy between $Q_{2 w} / D$ and $Q_{2 n} / D$. It is clearly shown that the effect of axial conduction decreases either as $\left|p_{s}\right|$ or as $D$ are increased. It may be also noted that the differences between 
$Q_{2 w} / D$ and $Q_{e n} / D$ are less than for natural convection, except for small spacing ( $D$ less than $\approx 2 \mathrm{~mm}$ ) at which the flow rate is strongly reduced, whatever $p_{s}$ in the range considered. Therefore, we plotted only the variations of $Q_{2 w} / D$ as function of $D$ for various $p_{s}$ in Fig. 9. As expected, this figure shows that the heat flux increases sharply when decreasing $p_{s}$ while $D_{\text {opt }}$ decreases. The variations of the mean flow velocity versus $D$ for various $p_{s}$ reported in Fig. 10 explain the increase in heat flux and decrease in axial conduction which may be considered negligible when $P e_{D}>100$, or $D \geq 9 \mathrm{~mm}, \geq 5.5 \mathrm{~mm}$ and $\geq 4 \mathrm{~mm}$ for $p_{s}=-0.1 P a,-0.4 P a$ and $-1 P a$, respectively.

Mereu et al. [31] investigated the optimal geometry of packages with fixed pumping power, i.e. when the flow is created by a fan or a pump. By denoting $\mathcal{W}_{m}=G_{v}\left|p_{s}\right|$ the pumping power for one channel $\left(G_{v}=\bar{w}\left(D_{\text {opt }} L\right)\right.$ being the volumetric flow rate), the relations given in [31] for $D_{\text {opt }}$ and $Q_{\max }$ can be rewritten as follows for negligible plate thickness $(e<<D)$ :

$$
D_{\text {opt }} \cong \mathbf{C W}_{m}^{-1 / 5} \quad \text { and } \quad Q_{\max } / D_{\text {opt }} \leq \mathbf{C C}^{\prime-1 / 3} \mathcal{W}_{m}^{2 / 5}
$$

where $\mathbf{C}=2.26^{6 / 5} \operatorname{Pr}^{-60 / 135}(\mu H)^{3 / 5} / \rho^{2 / 5}$ and $\mathbf{C}^{\prime}=0.65 k_{0} \Delta T \operatorname{Pr}^{17 / 27} \rho^{2 / 3} / \mu$.

Using the set of physical data fixed in the present study, we obtain $\mathbf{C}=1.0510^{-3}$ and $\mathbf{C C}^{\prime-1 / 3}=3.2410^{5}$. Therefore, comparisons between our predictions and those based on Eq. 38 can be made. To this end, the results reported in Table 6 were correlated as $D_{\text {opt }}=\alpha \mathcal{W}_{m}^{n_{1}}$ and $Q_{2 w} / D_{\text {opt }}=\beta \mathcal{W}_{m}^{n_{2}}$. We found for $D_{\text {opt }}: \alpha=1.3110^{-3}, n_{1}=-0.197$, and for $Q_{2 w} / D_{o p t}: \beta=2.3510^{5}, n_{2}=0.394$. The exponents are thus in excellent agreement with those in Eq. 38 while the discrepancies on both coefficients are quite large but of same order of magnitude. In conclusion, the overall discrepancies between our results and those based on Eq. 38 can be estimated to be about 20\%. The values corresponding to the theoretical solution (Eq. 38) are reported in Fig. 8a and 8b for $p_{s}=-0.1 P a$ and $p_{s}=-1 P a$, respectively. In comparison with the numerical solution, $D_{\text {opt }}$ is underestimated while $Q_{2 w} / D_{\text {opt }}$ is overestimated. 


\subsection{Mixed convection}

Since comparisons between the results obtained for mixed convection with $\left|p_{s}\right|<0.1 \mathrm{~Pa}$ does not differ significantly from those for natural convection (Fig. 5), and since the results for forced convection with $\left|p_{s}\right|>1 P a$ show that natural convection has a weak effect, we consider now the domain $\left|p_{s}\right| \in\left[\begin{array}{llll}0.1 & P a, 1 & P a\end{array}\right]$ in which natural and forced convection have comparable strengths.

It should be emphasized that the pressure boundary conditions used in the present study lead automatically to an increase of the mass flow rate when considering mixed convection instead of natural or forced convection. According to the usual terminology, we are thus considering "aiding-buoyancy" flows only, for which any recirculating flow may appear in the channel entrance region owing to the pressure boundary conditions applied. As it is well established, reverse flows never occur for identical temperature of the channel walls.

Variations of $Q_{2 w} / D$ as function of $D$ for $p_{s}=-0.2 P a$ and $p_{s}=-1 P a$ are shown in Figs. 11a and 11b. These figures indicate that :

- first, the effect of natural convection is significant for $p_{s}=-0.2 \mathrm{~Pa}$ since the differences between $Q_{2 w, \text { mixed }} / D$ and $Q_{2 w, \text { forced }} / D$ are large. On the other hand, this difference is rather small for $p_{s}=-1 P a$. Therefore, it is not relevant to perform computations for $p_{s}<-1 P a$ in the configuration studied.

- second, as expected $D_{\text {opt }}$ is the smallest for mixed convection. However, the difference between the values for forced and mixed convection decreases as $\left|p_{s}\right|$ is increased as can be seen by comparing Tables 5 and 7 .

A single correlation for natural, mixed and forced convection domains was developed by Bello-Ochende and Bejan [36]. Its range of application is $10^{-3} \leq \operatorname{Pr} \leq 10^{2}, 10^{5} \leq R a_{H} \leq 10^{7}$ 
and $10^{5} \leq B e \leq 10^{7}$. It can be written as

$$
D_{\text {opt }}=1.7610^{-4} A(\operatorname{Pr}) C\left(\eta_{b}\right) H B e^{-1 / 4} \quad Q_{\max } / D_{o p t}=0.0011 B(\operatorname{Pr}) E\left(\eta_{b}\right)\left(\frac{k_{0} \Delta T}{H}\right) B e^{1 / 2}
$$

where $A(P r)$ and $B(P r)$ are as in Eq. 32 and $\eta_{b}=\left(R a_{H} / B e\right)^{1 / 4} \cdot C\left(\eta_{b}\right)$ and $E\left(\eta_{b}\right)$ are given by

$$
C\left(\eta_{b}\right)=\left[17.69^{-2.08}+\left(28.27 / \eta_{b}\right)^{-2.08}\right]^{-1 / 2.08} \quad E\left(\eta_{b}\right)=\left[511^{0.9}+\left(110.5 \eta_{b}^{2}\right)^{0.9}\right]^{1 / 0.9}
$$

For the set of physical data fixed in the present study, we obtain $A(\operatorname{Pr})=307.2, B(\operatorname{Pr})=$ 8.875, $\eta_{b}=44.03 B e^{-1 / 4}$ and $B e \approx 2.4510^{7} \Delta p(\Delta p$ in $P a)$. From our computations, $\Delta p=-\frac{1}{2} \rho_{0} \bar{w}_{0}^{2}-p_{s}$ varies between $6.810^{-2} \mathrm{~Pa}$ and $7.9610^{-1} \mathrm{~Pa}$ for $D_{\text {opt }}$ when $0.1 \mathrm{~Pa} \leq$ $\left|p_{s}\right| \leq 1 \mathrm{~Pa}$. We conclude that $1.6710^{6} \leq \mathrm{Be} \leq 1.9510^{7}$ and, $0.663 \leq \eta_{b} \leq 1.226$ in that range of $p_{s}$. Therefore, forced convection and natural convection are of same order of magnitude in our domain of computations. Unfortunately, application of Eq. 39 leads to completely different results from those reported in Table 7.

From Eq. 37 and Eq. 39 it is readily found that

$$
D_{\text {opt }, \text { mixed }} / D_{\text {opt, forced }}=0.0154 C\left(\eta_{b}\right) \quad \text { with } C\left(\eta_{b}\right)<17.69
$$

If natural and forced convection strengths are of same order $\left(\eta_{b}=1\right)$, Eq. 41 indicates that $D_{\text {opt,mixed }} \approx 0.27 D_{\text {opt,forced }}$. Such a prediction does not agree with our results. For example, the present computations carried out for $p_{s}=-0.1 P a$ leads to $\eta_{b}=1.226$. The correlation given by Eq. 40 yields $C\left(\eta_{b}\right)=14.2$ and, $D_{\text {opt,mixed }} \approx 0.22 D_{\text {opt,forced }}$ while we found (see Tables 5 and 7) $D_{\text {opt,forced }}=7.57 \mathrm{~mm}$ and $D_{\text {opt,mixed }}=5.95 \mathrm{~mm}$, i.e. $D_{\text {opt }, \text { mixed }}=0.79 D_{\text {opt }, \text { forced }}$.

Figure $12 \mathrm{a}$ presents the $D_{\text {opt }}$-variations versus $\left|p_{s}\right|$, included is the natural convection result corresponding to $p_{s}=0$. Figure 12 a shows that $D_{\text {opt }}$ decreases when $\left|p_{s}\right|$ increases while Figure $12 \mathrm{~b}$ shows that $Q_{2 w} / D_{\text {opt }}$ increases with $\left|p_{s}\right|$, the effect of buoyancy force being 
rather small for $p_{s}=-0.1 P a$. Therefore, the last question to be considered is to look for a true optimal spacing by taking into account not only the increase of thermal efficiency but also the importance of mechanical load. To this end, it is convenient to make a distinction between thermal and overall efficiencies.

\subsubsection{Efficiency}

- Thermal efficiency

The design problem considered is a volume of width $W$ cooled with a stack of $n$ parallel, isothermal boards of thickness $e$, much smaller than the spacing $D$ (Fig. 1). The total heat flux $Q_{T}$ removed from the entire stack of heated surfaces having a total heat transfer area $S_{T}=2 n(H \times L)$ is :

$$
Q_{T}=n Q_{2 w}=\left(\frac{W-e}{D+e}\right) Q_{2 w} \quad\left(W / m^{2}\right)
$$

The optimal spacing corresponds to the maximum of $Q_{T}$ (or of $(W / D) Q_{2 w}$ if the thickness of the plates is such as $e<<D)$.

- Overall efficiency

For forced or mixed convection, the pumping power required to create a flow or to increase the pure natural velocity can be deduced from a kinetic energy balance based on the conservation of mechanical energy.

The kinetic energy balance is obtained by multiplying the momentum equation by the velocity and then by integrating over the whole fluid domain. By taking into account the boundary conditions for pressure and velocity components used in the present work, the 
kinetic energy balance reduces to:

$$
\begin{aligned}
\underbrace{\left|p_{s}\right| G_{v}}_{(a)}= & \underbrace{\int_{-D / 2}^{D / 2} \rho_{0} \frac{w^{3}(x, H)}{2} d x}_{(b)}+\underbrace{\int_{0}^{H} \int_{-D / 2}^{D / 2} \frac{1}{2} \overline{\bar{\tau}}: \overline{\bar{d}} d x d z}_{(c)} \\
& -\underbrace{\int_{0}^{H} \int_{-D / 2}^{D / 2} \rho_{0} g \beta\left(T(x, z)-T_{0}\right) w(x, z) d x d z}_{(d)}
\end{aligned}
$$

where $G_{v}=\bar{w}(D L)$ is the volumetric flow rate, $\overline{\bar{\tau}}=2 \mu \overline{\bar{d}}$ is the viscous stress tensor and $\overline{\bar{d}}$ the deformation velocity tensor. The term $(a)$ in Eq. (43) represents the mechanical power supplied by a device to the fluid. In the case of fins, this device could be a fan, for example. In the natural convection framework, $(a)$ is zero and it becomes positive in mixed convection. This power is balanced by two dissipation terms and one production term. Contribution (b) represents the kinetic power lost by the fluid at the outlet section and (c) denotes the power irreversibly lost by viscous friction. Note that $(c)$ is negligibly small in the energy equation, and has been neglected, whereas it must introduced in order to properly balance the kinetic energy equation. The last contribution $(d)$ corresponds to the production term of energy which must be accounted for in natural or mixed convection, when its contribution is significant. From a numerical point of view, the balance of kinetic energy (Eq. 43) is satisfied within less than $1 \%$ for the meshes used in the present study.

Therefore, the pumping power $\mathcal{W}_{m}$ for the entire stack of $n$ boards can be written as $\mathcal{W}_{m}=n\left|p_{s}\right| G_{v}=n\left|p_{s}\right| \bar{w}(D L)$. For a given value of $p_{s}$, the effect of natural convection is to increase the inlet velocity corresponding to forced convection (a result which cannot be found by prescribing a pressure difference or an inlet velocity, as it has been assumed in most of the studies on mixed convection). Consequently, the pumping power is necessarily higher for mixed convection than for forced convection since $\bar{w}$ increases. However, the total heat flux $Q_{T}$ is also increased. Table 8 allows comparisons between the increases in heat fluxes and in pumping powers for various pressure drops in the case $D=5 \mathrm{~mm}$. As can be seen, the increase in heat flux is more than four orders in magnitude larger than the increase 
in $\mathcal{W}_{m}$. The overall efficiency of a vertical stack of isothermal plates (mixed convection) is thus automatically better than that for an horizontal stack (forced convection) provided that buoyancy assisted flows are considered.

When considering mixed convection, it can be expected that the increase in mechanical power expense is compensated by a significant increase in heat transfer rate in comparison with natural convection. The efficiency of the system may be thus evaluated as

$$
\eta\left(p_{s}\right)=\frac{\left(n_{\text {opt }} Q_{2 w}\right)_{\text {mixed }}-\left(n_{\text {opt }} Q_{2 w}\right)_{\text {natural }}}{\left|p_{s}\right| L\left((n D)_{\text {opt }} \bar{w}\right)_{\text {mixed }}}
$$

where $n_{\text {opt }}$, function of $p_{s}$ and $H$, is the number of channels for a stack of width $W$ working in optimal conditions $\left(n_{\text {opt }}\right.$ is the integer lying in the interval $\left.\left[(W-e) /\left(D_{\text {opt }}+e\right) \pm 0.5\right]\right)$.

Let us consider a practical application by assuming that $W=100 \mathrm{~mm}$ and $e=1 \mathrm{~mm}$ (air as the working fluid, $\Delta T=40 \mathrm{~K}$, channel height $H=0.1 \mathrm{~m}$, unit spanwise depth $L=1 \mathrm{~m}$ ). For natural convection, it has been found that $D_{o p t}=6.52 \mathrm{~mm}$ and $Q_{2 w}=46 \mathrm{~W}$ : therefore, $\left(n_{\text {opt }} Q_{2 w}\right)_{\text {natural }} \approx 600 \mathrm{~W}$. For mixed convection, the values of $D_{\text {opt }}$ are reported in Table 7 . Since $D_{\text {opt }}$ decreases as $\left|p_{s}\right|$ increases, $n_{\text {opt }}$ is maximum for $\left|p_{s}\right|=1 P a$. When $\left|p_{s}\right|>1 P a$, $n_{\text {opt }}$ should increase as $\Delta p_{s}^{1 / 4}$ according to Eq. 35 owing to the negligible effect of natural convection. The augmentation with the pressure drop both in $n_{\text {opt }}$ and in the heat flux transferred along each of the channel result in large increases in the overall heat flux, $Q_{T}$. However, the pumping power augments more quickly than $Q_{T}$. As a result, the efficiency as defined in Eq. 44 decreases. $\eta\left(p_{s}\right)$ is plotted in Fig. 13 versus $p_{s}$ by taking into account the various approximations introduced in its definition. The high value of $\eta\left(p_{s}\right)$ (of the order of $10^{5}$ ) exhibits a decrease as $\approx p_{s}^{-2 / 3}$ for the largest values of $\left|p_{s}\right|$, in rather good agreement with what could be easily found by using the analysis by Bejan and Scubbia [30]. 


\section{Conclusion}

The purpose of this work was to numerically analyze the optimum spacing of a stack of symmetrically isothermal plates cooled by natural, forced or mixed convection. This idealized configuration has a number of applications in the convective cooling of electronic equipments. The governing equations were solved in their full elliptic form by assuming steady, laminar incompressible flows, constant thermophysical properties, and by invoking the Boussinesq approximation for natural and mixed convection. We implemented specific pressure boundary conditions in order to make relevant comparisons between the results obtained for the three modes of convective cooling, including very small flow rates. In these cases, it was demonstrated that axial heat conduction plays a significant role and that an appropriate modeling of the thermal boundary condition is required. The main concluding remarks are as follows:

- 1 The present computations are in agreement with the optimal plate spacings predicted by using asymptotic analyses for natural convection [26],[25] and forced convection [30].

- 2 An optimal plate spacing still exists for mixed convection : it is smaller than for forced convection. The maximal heat flux is increased due to the combined effects of pressure and buoyancy forces.

- 3 The heat flux transferred by mixed convection is considerably higher than that by natural convection : for the specific case considered, a small pressure drop at the outlet section (i.e. $-1 P a$ ) is enough for increasing the heat flux by a factor of three.

\section{REFERENCES}

[1] B. Balunov, A. Babykin, R. Rybin, B. Krylov, V. Tanchuck and S. Grigoriev, Heat transfer at mixed convection in vertical and inclined flat channels of the vacuum chamber of the ITER international thermonuclear reactor, High Temperature 42 (2004) 126-133.

[2] W. Aung, G. Worku, Theory of fully developed, combined convection including flow reversal, ASME J. Heat Transfer 108 (1986) 485-488.

[3] W. Aung, G. Worku, Developing flow and flow reversal in a vertical channel with asymmetric wall temperatures, ASME J. Heat Transfer 108 (1986) 289-304. 
[4] W. Aung, G. Worku, Mixed convection in ducts with asymmetric wall heat fluxes, ASME J. Heat Transfer 109 (1987) 947-951.

[5] J. Padet, R. M. Cotta, N. C. Chereches, N. El Wakil, Convection laminaire interne: critères de sélection pour distinguer les régimes de convection naturelle, mixte ou forcée, Congrès Français de Thermique, SFT 2005, Reims, (2005).

[6] C. Padet, E. M. Mladin, J. Padet, A. Dobrovicescu, Minimization of entropy production in fully developped mixed thermal convection, Int. Symp. on Convective Heat and Mass Transfer in Sustainable Energy, Tunisia, (2009)

[7] J. Padet, R. M. Cotta, E. M. Mladin, Un autre regard sur la convection mixte, Comptes Rendus COFRET'10, Iasi, Roumanie, 2010.

[8] S. Yao, Free and forced convection in the entry region of a heated vertical channel, Int. J. Heat Mass Transfer 26 (1983) 65-72.

[9] C. H. Cheng, S. Huang, W. Aung, Enhancement of FLARE method for predicting buoyancy-induced flow reversal in vertical ducts via parabolic model, Numer. Heat Transfer, Part B, 31 (1997) 327-345.

[10] Y. N. Jeng, J. L. Chen, W. Aung, On the Reynolds-number independence of mixed convection in a vertical channel subjected to asymmetric wall temperatures with and without flow reversal, Int. J. Heat Fluid Flow 13 (1992) 329-339.

[11] C. S. Yang, D. Z. Jeng, K. A. Yih, C. Gau, W. Aung, Numerical and analytical study of reversed flow and heat transfer in a heated vertical duct, ASME J. Heat Transfer 131 (2009) 072501-1 072501-9.

[12] G. Desrayaud, G. Lauriat, Flow reversal of laminar mixed convection in the entry region of symmetrically heated, vertical plate channels, Int. J. Therm. Sci. 48(11) (2009) 2036-2045.

[13] K. T. Lee, H. L. Tsai, W. M. Yan, Mixed convection heat and mass transfer in vertical rectangular ducts, Int. J. Heat Mass Transfer, 40 (7) (1997) 1621-1631.

[14] Z. Ait Hammou, B. Benhamou, N. Galanis, J. Orfi, Laminar mixed convection of humid air in a vertical channel with evaporation or condensation, Int. J. Therm. Sci. 43(6)(2004) 531-539.

[15] N. Laaroussi, G. Lauriat, G. Desrayaud, Effects of variable density for film evaporation on laminar mixed convection in a vertical channel, Int. J. Heat Mass Transfer 52 (2009) 151-164.

[16] Y. C. Chen, J. N. Chung, The linear stability of mixed convection in a vertical channel flow, J. Fluid Mech. 325 (1996) 29-51.

[17] Ch. Guillet, Th. Mare, C. T. Nguyen, Application of a non-linear local analysis method for the problem of mixed convection instability, Int. J. Non-Linear Mech. 42 (2007) 981-988.

[18] B. R. Morton, D. B. Ingham, D. J. Keen, P. J. Heggs, Recirculating combined in laminar pipe flow, J. Heat Transfer 111 (1989) 106-113.

[19] D. B. Ingham, D. J. Keen, P. J. Heggs, B. R. Morton, Recirculating pipe flows, J. Fluid Mech. 213 (1990) 443-464.

[20] C. Gau, K. Yih and W. Aung, Measurements of heat transfer and flow structure in heated vertical channels with buoyancy assisted and opposed flows, AIAA J. Thermophys. Heat Transfer 6 (1992) 707712 .

[21] C. Gau, K. Yih and W. Aung, Reversed flow structure and heat transfer measurements for buoyancyassisted convection in a heated vertical duct, ASME J. Heat Transfer 114 (1992) 928-935.

[22] T. M. Huang, C. Gau, W. Aung, Mixed convection flow and heat transfer in a heated convergent channel, Int. J. Heat Mass Transfer 38 (1995) 24445-2456.

[23] M. A. Bernier, B. R. Baliga, Visualization of upward mixed-convection flows in vertical pipes using a thin semitransparent gold-film heater and dye injection, Int. J. Heat Fluid Flow 13(4) (1992) 241-249.

[24] W. Elenbaas, Heat dissipation of parallel plates by free convection, Physica 9 (1) (1942) 1-28.

[25] A. Bar-Cohen, W. M. Rohsenow, Thermally optimum spacing of vertical, natural convection cooled, parallel plates, ASME J. Heat Transfer 106 (1984) 116-123.

[26] A. Bejan, Convection Heat Transfer, Wiley, New York, (1984) Problem 11, p.157, Chpt 4.

[27] A. Bejan, Convection Heat Transfer, 3rd ed., Wiley, Hoboken (2004).

[28] A. Bejan, S. Lorente, Design with Constructal theory, Wiley, Hoboken (2008).

[29] N. K. Anand, S. H. Kim, L. S. Fletcher, The effect of plate spacing on free convection between heated 
parallel plates, ASME J. Heat Transfer, 114 (1992) 515-518.

[30] A. Bejan, E. Sciubba, The optimal spacing of parallel plates cooled by forced convection, Int. J. Heat Mass Transfer 35 (1992) 3259-3264.

[31] S. Mereu, E. Sciubba, A. Bejan, The optimal cooling of a stack of heat generating boards with fixed pressure drop, flowrate or pumping power, Int. J. Heat Mass Transfer, 36 (1993) 3677-3686.

[32] A. Campo, Bounds for the optimal conditions of forced convective flows inside multiple channels whose plates are heated by a uniform flux, Int. Comm. Heat Mass Transfer, 26 (1999) 105-114.

[33] J. C. Watson, N. K. Anand, L. S. Fletcher, Mixed convective Heat Transfer between a series of vertical parallel plates with planar heat sources, ASME J. Heat Transfer, 118 (1996) 984-990.

[34] A. Bejan, G. A. Ledezma, Thermodynamic optimization of cooling techniques for electronic packages, Int. J. Heat Mass Transfer, 39 (1996) 1213-1221.

[35] A.K. da Silva, A. Bejan, Constructal multi-scale structure for maximal heat transfer density in natural convection, Int. J. Heat and Fluid Flow, 26 (2005) 34-44.

[36] T. Bello-Ochende, A. Bejan, Optimal spacings for mixed convection, ASME J. Heat Transfer, 126 (2004) 956-962.

[37] A. Barletta, E. Zanchini, On the choice of the reference temperature for fully-developed mixed convection in a vertical channel, Int. J. Heat Mass Transfer 42 (1999) 3169-3181.

[38] H. Sadat, P. Salagnac, Calcul des flux aux parois présentant des singularités, Int. J. Heat Mass Transfer 40 (1997) 4255-4262.

[39] D. Naylor, J. M. Floryan, J. D. Tarasuk, A numerical study of developing free convection between isothermal plates, ASME J. Heat Transfer, 113 (1991) 620-626.

[40] B. Morrone, A. Campo, O. Manca, Optimum plate separation in vertical parallel-plate channels for natural convective flows: Incorporation of large spaces at the channel extremes, Int. J. Heat Mass Transfer, 40 (1997) 993-1000.

[41] S. K. S. Boetcher, E. M. Sparrow, Buoyancy-induced flow in an open-ended cavity: Assessment of a similarity solution and of numerical simulation models, Int. J. Heat Mass Transfer, 52 (2009) 3850-3856.

[42] G. Desrayaud, G. Lauriat, A numerical study of partially open enclosures with a conducting side-wall, ASME J. Heat Transfer, 126 (2004) 76-83.

[43] K. Khanafer, K. Vafai, Buoyancy-driven flow and heat transfer in open-ended enclosures: elimination of the extended boundaries, Int. J. Heat Mass Transfer, 43 (2000) 4087-4100.

[44] K. Khanafer, K. Vafai, Effective boundary conditions for buoyancy-driven flows and heat transfer in fully open-ended two-dimensional enclosures, Int. J. Heat Mass Transfer, 45 (2002) 2527-2538.

[45] A. Auletta, O. Manca, Heat and fluid flow resulting from the chimney effect in a symmetrically heated vertical channel with adiabatic extensions, Int. J. Thermal Sciences, 41 (2002) 1101-1111.

[46] A. Andreozzi, B. Buonomo, O. Manca, Thermal and fluid dynamic behaviours in symmetrical heated channel-chimney systems, Int. J. Num. Methods Heat Fluid Flow, 20 (2010) 811-833.

[47] A. Andreozzi, B. Buonomo, O. Manca, Numerical study of natural convection in vertical channels with adiabatic extensions downstream, Num. Heat Transfer, Part A, 47 (2005) 741-762.

[48] A. Andreozzi, O. Manca, V. Naso, Natural convection in vertical channels with an auxiliary plate, Int. J. Num. Methods Heat Fluid Flow, 12 (2002) 716-734. 


\section{List of Tables}

1 Pure conductive wall heat flux $Q_{\text {cond }}(W)$ for $D=610^{-3} \mathrm{~m}, H=0.1 \mathrm{~m}$, $L=1 \mathrm{~m}$ and $\Delta T=40 \mathrm{~K}$ according to the mesh refinement $\left(n_{z}=50 n_{x}\right)$. Order $\alpha$ of convergence of the numerical scheme and Richardson-extrapolated

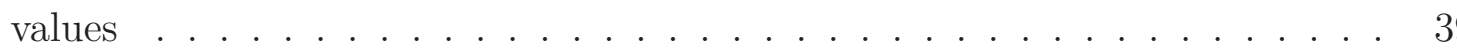

2 Natural convection for $D=610^{-3} \mathrm{~m}, H=0.1 \mathrm{~m}, L=1 \mathrm{~m}$ and $\Delta T=40 \mathrm{~K}$ $\left(n_{z}=50 n_{x}\right)$. Convective flux at the isothermal wall, $Q_{2 w}(W)$, enthalpy flux, $Q_{e n}(W)$, and average velocity, $\bar{w}(\mathrm{~m} / \mathrm{s})$. Order $\alpha$ of convergence of the numerical scheme and Richardson-extrapolated values. . . . . . . . . . .

3 Pure conductive wall heat flux $Q_{\text {cond }}(W)$ for $D=610^{-3} \mathrm{~m}, H=0.1 \mathrm{~m}$, $L=1 \mathrm{~m}$ and $\Delta T=40 \mathrm{~K}$ with a regularized temperature distribution (Eq. 26) according to the mesh refinement $\left(n_{z}=50 n_{x}\right)$. Order $\alpha$ of convergence of the numerical scheme and Richardson-extrapolated values. . . . . . . . . . . . .

4 Natural convection: comparisons between the mean Nusselt number defined by Eq. 28 and the numerical values $N u_{2 w}$ and $N u_{e n}$ based on Eqs. 13 and 14.40

5 Forced convection: comparisons between analytical solutions $\left(D_{o p t, a}\right.$ and $Q_{\max } / D_{o p t}$, Eq. 35 and 36$)$ and numerical solutions: $D_{\text {opt }}(m m)$ and $Q_{2 w} / D_{o p t}(W / m) . \quad 40$

6 Forced convection: optimal plate-spacing, maximum heat flux, volumetric flow rate and pumping power for various pressure drops at the outlet section. 40

$7 \quad$ Mixed convection: effect of $p_{s}$ on $D_{o p t}(m m)$ and $Q_{2 w} / D_{o p t}(W / m)$. . . . 41

8 Comparison between the increases in heat flux and in pumping power versus the pressure drop $(D=5 m m, L=1 m) \ldots \ldots . \ldots . \ldots 41$

9 Mixed convection: optimal number of channels, average velocity, overall heat flux and pumping power for a stack of isothermal plates working in optimal conditions according to the pressure drop. 


\section{List of Figures}

1 Schematic of the array of vertical isothermal plates and boundary conditions. 42

2 Natural convection: variations of heat flux versus the number of grid points in the $x$-direction $\left(n_{z}=50 n_{x}\right)$ for $D=6 m m, H=0.1 m, L=1 m, \Delta T=40 \mathrm{~K}$. $Q_{2 w}$ is the wall heat flux for non-regularized wall temperature (Eq. 25) or for regularized wall temperature (Eq. 27 ). $Q_{e n}$ is the enthalpy flux (Eq. 14). . .

3 Natural convection: comparison between the analytical $\left(\bar{w}_{a}\right.$, Eq. 29) and numerical $(\bar{w})$ solutions of the mean flow velocity versus the plate spacing. .

4 Natural convection: temperature profile at the outlet section for various plate spacings. . . . . . . . . . . . . . . . . .

5 Natural convection: variations of the ratios $Q / D$ with the plate spacing. $Q_{a}$ and $Q_{b}$ are the asymptotic analytical solutions (Eq. 30), $Q_{2 w}$ and $Q_{e n}$ are given by Eqs. 13 and 14, and $Q_{\text {cond }}$ by Eq. 27. The cross symbol is for $D_{\text {opt }}$ and $Q_{\max } / D_{\text {opt }}$ based on Eq. 32 .

6 Natural convection: variations of the ratios $Q / D$ with the plate spacing. $Q_{c}$ is the analytical solution (Eq. 31), $Q_{2 w}$ and $Q_{e n}$ are given by Eqs. 13 and 14 .

$7 \quad$ Natural convection: axial velocity and temperature profiles at various heights for the optimal spacing, $D_{\text {opt }}=6.62 \mathrm{~mm} \ldots \ldots \ldots \ldots \ldots$

8 Forced convection: variations of the ratios $Q / D$ with the plate spacing for $p_{s}=-0.1 P a$ and for $p_{s}=-1 P a\left(Q_{a}\right.$ and $Q_{b}$ are the asymptotic analytical solutions, $Q_{2 w}, Q_{e n}$ are given by Eqs. 13 and 14, respectively). The cross symbols are for the analytical solutions given by Eq. 37 [36] and Eq. 38 [31].

9 Forced convection: variations of the ratio $Q_{2 w} / D$ versus the plate spacing for

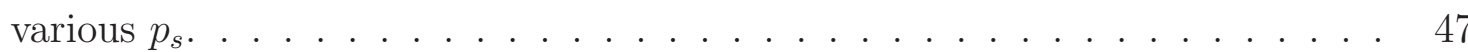

10 Forced convection: variations of the mean flow velocity versus the plate spacing for various $p_{s} \ldots \ldots \ldots \ldots \ldots \ldots \ldots \ldots \ldots \ldots \ldots \ldots \ldots$

11 Mixed convection : variations of the ratio $Q_{2 w} / D$ versus the plate spacing for forced and mixed convection. . . . . . . . 
12 Mixed convection : variations of $D_{\text {opt }}$ and $Q_{2 w} / D_{o p t}$ versus $p_{s}$ for forced and mixed convection. . . . . . . . . . . . . . . . . . . . . . . . 49

13 Variations of overall efficiency $\eta$ versus $p_{s}$ for mixed convection. . . . . . . . 50 


\section{TABLES}

\begin{tabular}{c|ccccc||cc}
$n_{x}$ & 10 & 20 & 40 & 80 & 160 & $\alpha$ & Extrap. \\
\hline$Q_{\text {cond }}$ & -6.78347 & -7.73104 & -8.66075 & & & $2.7458510^{-2}$ & 53.5420 \\
& & -7.73104 & -8.66075 & -9.58505 & & $8.4108710^{-3}$ & -167.667 \\
& & & -8.66075 & -9.58505 & -10.50776 & $2.4860710^{-3}$ & -545.507
\end{tabular}

Table 1: Pure conductive wall heat flux $Q_{\text {cond }}(W)$ for $D=610^{-3} m, H=0.1 m, L=1 \mathrm{~m}$ and $\Delta T=40 \mathrm{~K}$ according to the mesh refinement $\left(n_{z}=50 n_{x}\right)$. Order $\alpha$ of convergence of the numerical scheme and Richardson-extrapolated values

\begin{tabular}{|c|c|c|c|c|c|c|}
\hline$n_{x}$ & 10 & 20 & 40 & 80 & $\alpha$ & Extrap. \\
\hline$Q_{2 w}$ & -43.4100 & -44.2962 & -45.2092 & & $-4.2969310^{-2}$ & -14.0963 \\
\hline$Q_{2 w}$ & & -44.2962 & -45.2092 & -46.1288 & $-1.0426110^{-2}$ & 81.5836 \\
\hline$Q_{\text {en }}$ & 40.3414 & 40.2699 & 40.2520 & & 1.99095 & 40.2459 \\
\hline$Q_{e n}$ & & 40.2699 & 40.2520 & 40.2477 & 2.07492 & 40.2464 \\
\hline $\bar{w}$ & 0.147638 & 0.147280 & 0.147190 & & 1.99445 & 0.147160 \\
\hline $\bar{w}$ & & 0.147280 & 0.147190 & 0.147168 & 2.01678 & 0.147160 \\
\hline
\end{tabular}

Table 2: Natural convection for $D=610^{-3} \mathrm{~m}, H=0.1 \mathrm{~m}, L=1 \mathrm{~m}$ and $\Delta T=40 \mathrm{~K}\left(n_{z}=50 n_{x}\right)$. Convective flux at the isothermal wall, $Q_{2 w}(W)$, enthalpy flux, $Q_{e n}(W)$, and average velocity, $\bar{w}(\mathrm{~m} / \mathrm{s})$. Order $\alpha$ of convergence of the numerical scheme and Richardson-extrapolated values.

\begin{tabular}{c|ccccc||cc}
$n_{x}$ & 10 & 20 & 40 & 80 & 160 & $\alpha$ & Extrap. \\
\hline$Q_{\text {cond }}$ & -4.87969 & -4.97384 & -5.00314 & & & 1.68449 & -5.01636 \\
& & -4.97384 & -5.00314 & -5.01110 & & 1.87876 & -5.01407 \\
& & & -5.00314 & -5.01110 & -5.01314 & 1.96323 & -5.01385
\end{tabular}

Table 3: Pure conductive wall heat flux $Q_{\text {cond }}(W)$ for $D=610^{-3} m, H=0.1 m, L=1 \mathrm{~m}$ and $\Delta T=40 \mathrm{~K}$ with a regularized temperature distribution (Eq. 26) according to the mesh refinement $\left(n_{z}=50 n_{x}\right)$. Order $\alpha$ of convergence of the numerical scheme and Richardson-extrapolated values. 


\begin{tabular}{c|l|l|ll}
\hline$D(m m)$ & $N u_{a}$ & & $N u_{e n}$ & $N u_{2 w}$ \\
\hline 1 & 0.0016 & & 0.0016 & 0.014 \\
3 & 0.125 & & 0.120 & 0.151 \\
5 & 0.782 & & 0.711 & 0.751 \\
7 & 1.638 & & 1.591 & 1.642 \\
9 & 2.280 & & 2.338 & 2.402 \\
10 & 2.563 & & 2.658 & 2.729
\end{tabular}

Table 4: Natural convection: comparisons between the mean Nusselt number defined by Eq. 28 and the numerical values $N u_{2 w}$ and $N u_{e n}$ based on Eqs. 13 and 14 .

\begin{tabular}{c|ccccc}
\hline$p_{s}(P a)$ & -0.1 & -0.2 & -0.4 & -0.8 & -1.0 \\
\hline $\bar{w}_{\text {opt }} \quad(\mathrm{m} / \mathrm{s})$ & 0.178 & 0.252 & 0.357 & 0.504 & 0.566 \\
$\Delta p=\left[\bar{p}(0)-p_{s}\right]_{\text {opt }} \quad(P a)$ & 0.081 & 0.161 & 0.323 & 0.646 & 0.807 \\
& & & & & \\
$D_{\text {opt,a }}($ Eq. 35) & 7.28 & 6.13 & 5.15 & 4.33 & 4.10 \\
$D_{\text {opt }}$ (present) & 7.57 & 6.38 & 5.38 & 4.52 & 4.29 \\
$Q_{\text {max }} / D_{\text {opt }}$ (Eq. 36) & $0.9110^{4}$ & $1.2910^{4}$ & $1.8210^{4}$ & $2.5810^{4}$ & $2.8810^{4}$ \\
$Q_{2 w} / D_{\text {opt }}$ (present) & $0.7010^{4}$ & $0.9910^{4}$ & $1.3910^{4}$ & $1.9710^{4}$ & $2.2110^{4}$
\end{tabular}

Table 5: Forced convection: comparisons between analytical solutions $\left(D_{o p t, a}\right.$ and $Q_{\text {max }} / D_{\text {opt }}$, Eq. 35 and 36 ) and numerical solutions: $D_{o p t}(\mathrm{~mm})$ and $Q_{2 w} / D_{o p t}(\mathrm{~W} / \mathrm{m})$.

\begin{tabular}{|c|c|c|c|c|c|}
\hline$p_{s}(P a)$ & -0.1 & -0.2 & -0.4 & -0.8 & -1.0 \\
\hline$D_{o p t}(m m)$ & 7.57 & 6.38 & 5.38 & 4.52 & 4.29 \\
\hline$Q_{2 w} / D_{o p t}(W / m)$ & $0.7010^{4}$ & $0.9910^{4}$ & $1.3910^{4}$ & $1.9710^{4}$ & $2.2110^{4}$ \\
\hline$G_{v}=[\bar{w}(D L)]_{o p t}\left(m^{3} / s\right)$ & $1.3510^{-3}$ & $1.6110^{-3}$ & $1.9210^{-3}$ & $2.2810^{-3}$ & $2.4310^{-3}$ \\
\hline $\mathcal{W}_{m}(W)$ & $1.3510^{-4}$ & $3.2210^{-4}$ & $7.6910^{-4}$ & $1.8310^{-3}$ & $2.4310^{-3}$ \\
\hline
\end{tabular}

Table 6: Forced convection: optimal plate-spacing, maximum heat flux, volumetric flow rate and pumping power for various pressure drops at the outlet section. 


\begin{tabular}{c|ccccc}
\hline$p_{s}(P a)$ & -0.1 & -0.2 & -0.4 & -0.8 & -1.0 \\
\hline$D_{\text {opt }}$ & 5.95 & 5.52 & 4.95 & 4.33 & 4.14 \\
$Q_{2 w} / D_{\text {opt }}$ & $0.9810^{4}$ & $1.2110^{4}$ & $1.5610^{4}$ & $2.1010^{4}$ & $2.3210^{4}$
\end{tabular}

Table 7: Mixed convection: effect of $p_{s}$ on $D_{o p t}(m m)$ and $Q_{2 w} / D_{o p t}(W / m)$.

\begin{tabular}{c|cccccc}
\hline$p_{s}(P a)$ & -0.1 & -0.2 & -0.4 & -0.6 & -0.8 & -1.0 \\
\hline$Q_{2 w, \text { mixed }}-Q_{2 w, \text { forced }}(W)$ & 20.920 & 14.848 & 8.041 & 5.064 & 3.570 & 2.719 \\
$\left|p_{s}\right| D L\left(\bar{w}_{\text {mixed }}-\bar{w}_{\text {forced }}\right)\left(10^{-4} W\right)$ & 0.483 & 0.778 & 1.116 & 1.308 & 1.439 & 1.540
\end{tabular}

Table 8: Comparison between the increases in heat flux and in pumping power versus the pressure drop $(D=5 \mathrm{~mm}, L=1 \mathrm{~m})$

\begin{tabular}{c|ccccc}
\hline$p_{s}(P a)$ & -0.1 & -0.2 & -0.4 & -0.8 & -1.0 \\
\hline \hline$n_{\text {opt }}$ & 14 & 15 & 16 & 18 & 19 \\
$\bar{w}_{\text {opt }}(\mathrm{m} / \mathrm{s})$ & 0.23 & 0.29 & 0.38 & 0.52 & 0.58 \\
$Q_{T}=n_{\text {opt }} Q_{2 w}(W)$ & 816 & 1001 & 1235 & 1636 & 1824 \\
$\mathcal{W}_{m}=\left|p_{s}\right| L(n D)_{\text {opt }} \bar{w}\left(10^{-3} W\right)$ & 1.9 & 4.7 & 12.1 & 32.4 & 45.5
\end{tabular}

Table 9: Mixed convection: optimal number of channels, average velocity, overall heat flux and pumping power for a stack of isothermal plates working in optimal conditions according to the pressure drop. 


\section{FIGURES}

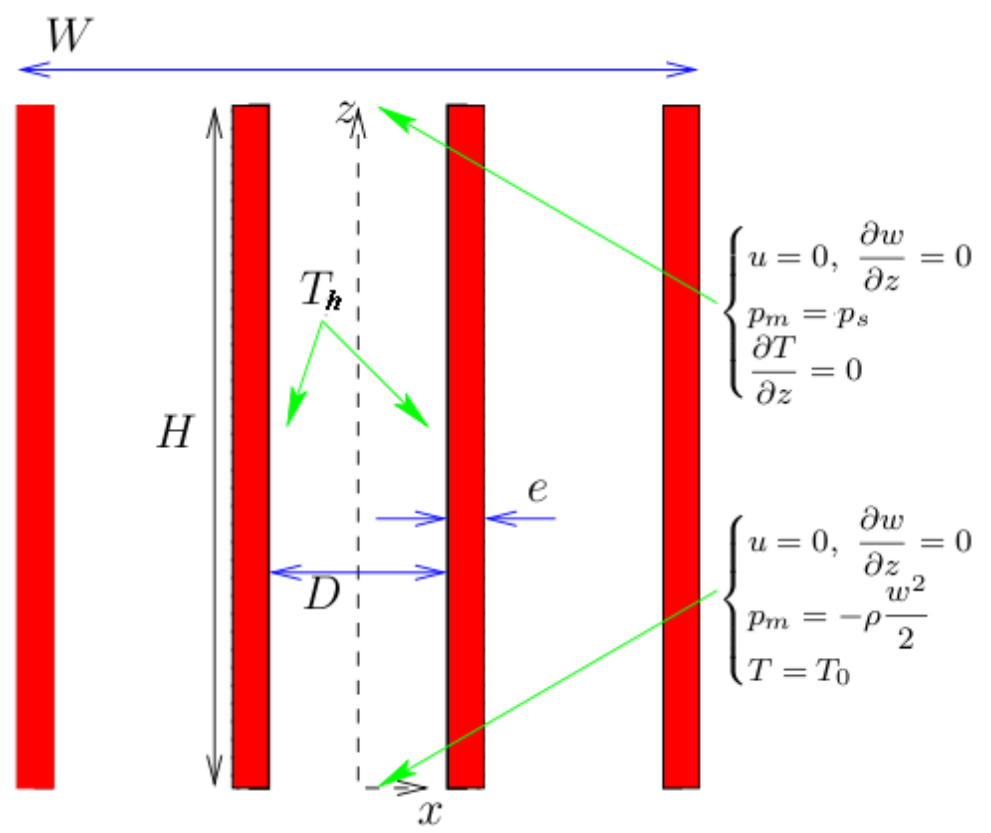

Figure 1: Schematic of the array of vertical isothermal plates and boundary conditions.

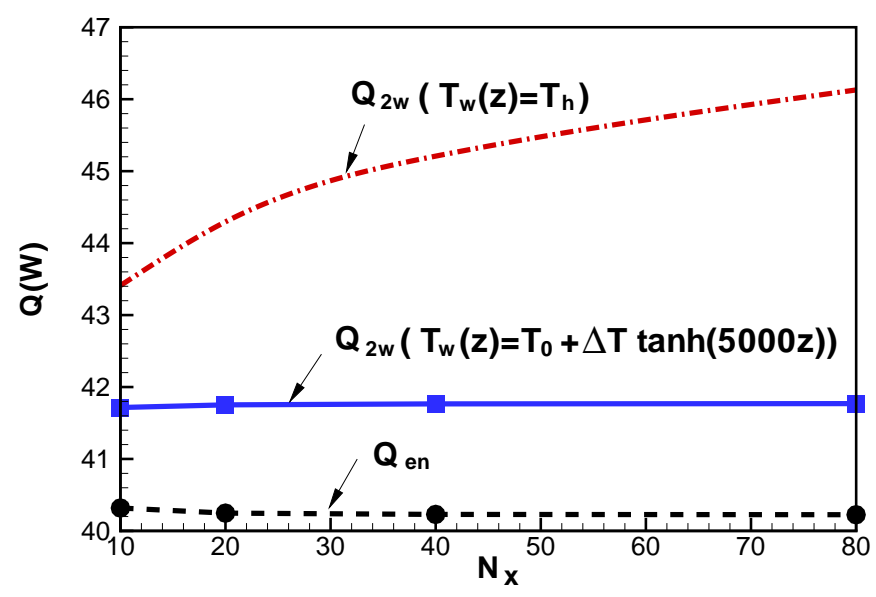

Figure 2: Natural convection: variations of heat flux versus the number of grid points in the $x$-direction $\left(n_{z}=50 n_{x}\right)$ for $D=6 \mathrm{~mm}, H=0.1 \mathrm{~m}, L=1 \mathrm{~m}, \Delta T=40 \mathrm{~K} . Q_{2 w}$ is the wall heat flux for non-regularized wall temperature (Eq. 25) or for regularized wall temperature (Eq. 27 ). $Q_{e n}$ is the enthalpy flux (Eq. 14). 


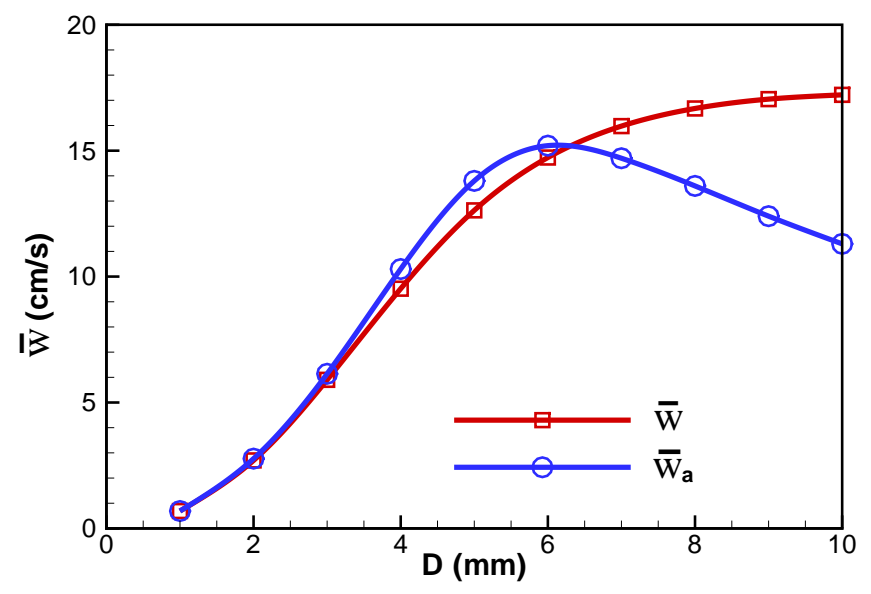

Figure 3: Natural convection: comparison between the analytical $\left(\bar{w}_{a}\right.$, Eq. 29$)$ and numerical $(\bar{w})$ solutions of the mean flow velocity versus the plate spacing.

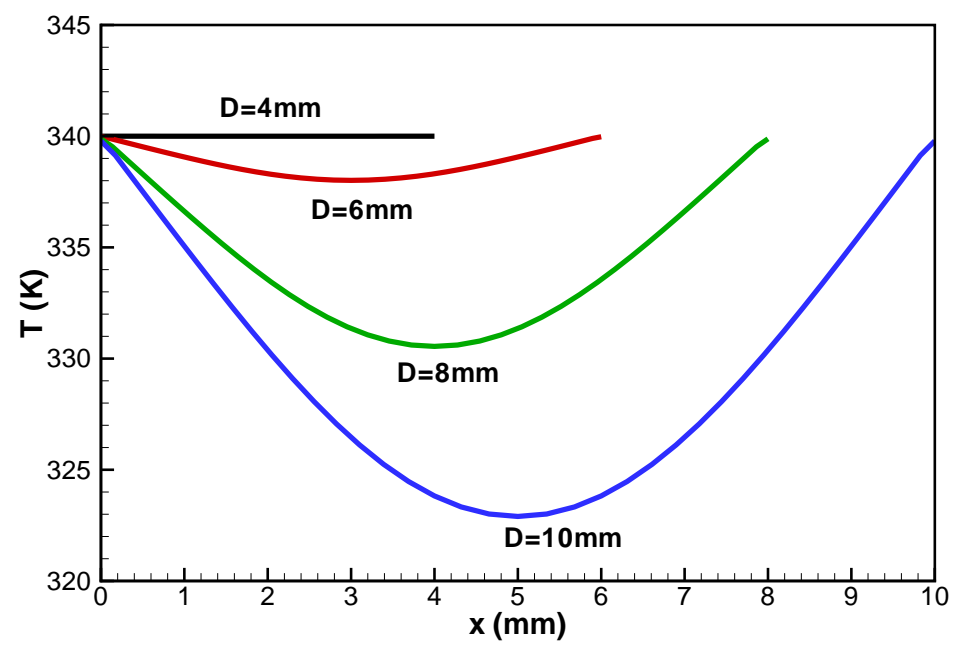

Figure 4: Natural convection: temperature profile at the outlet section for various plate spacings. 


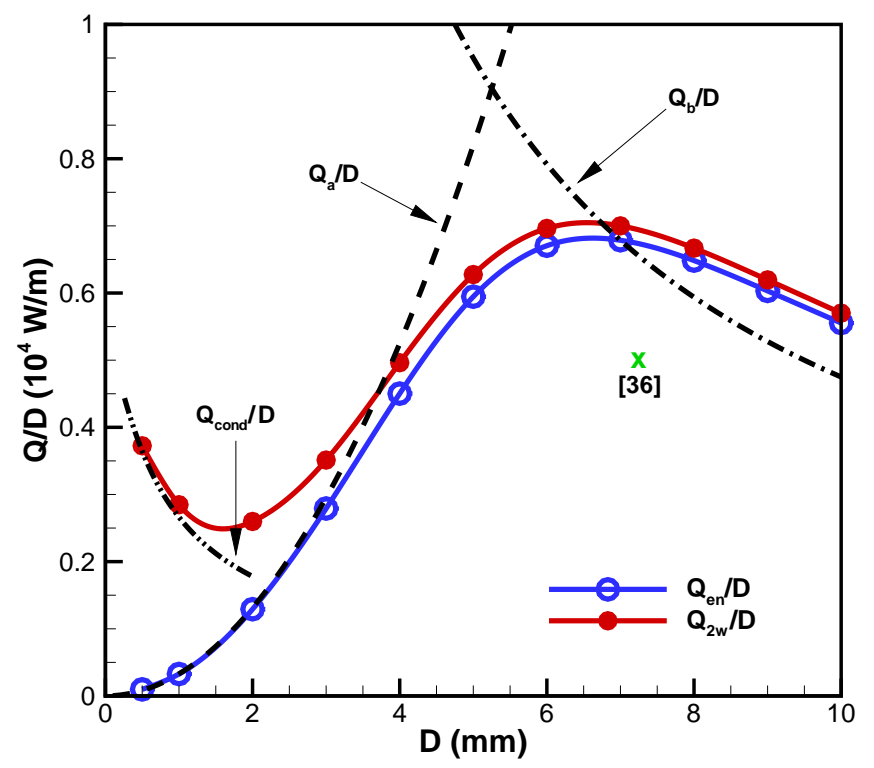

Figure 5: Natural convection: variations of the ratios $Q / D$ with the plate spacing. $Q_{a}$ and $Q_{b}$ are the asymptotic analytical solutions (Eq. 30), $Q_{2 w}$ and $Q_{e n}$ are given by Eqs. 13 and 14, and $Q_{\text {cond }}$ by Eq. 27. The cross symbol is for $D_{o p t}$ and $Q_{\max } / D_{\text {opt }}$ based on Eq. 32 .

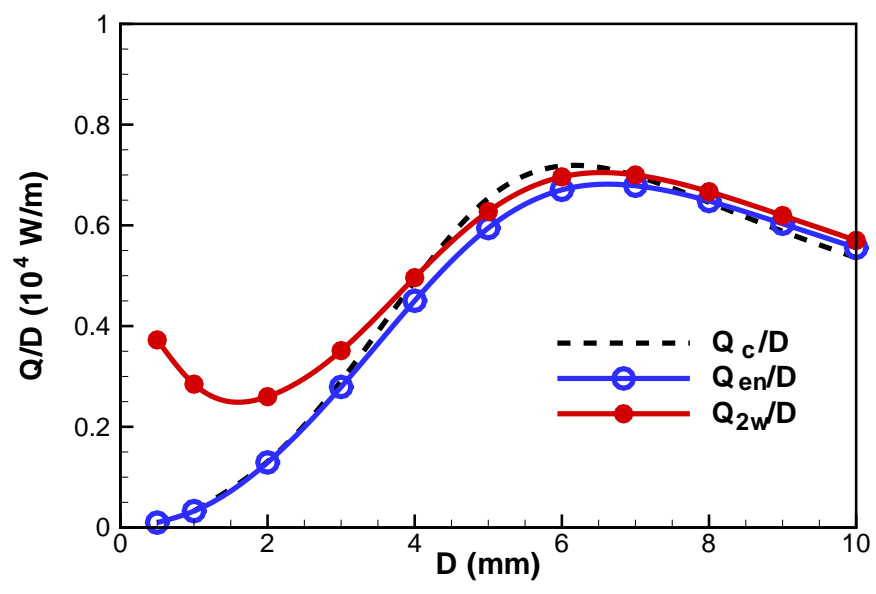

Figure 6: Natural convection: variations of the ratios $Q / D$ with the plate spacing. $Q_{c}$ is the analytical solution (Eq. 31), $Q_{2 w}$ and $Q_{e n}$ are given by Eqs. 13 and 14 . 


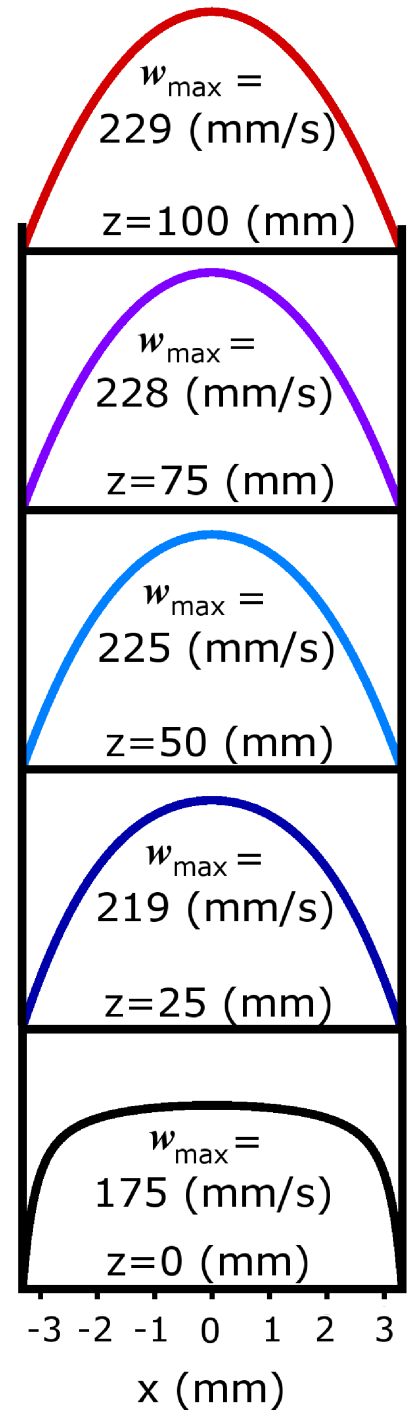

(a) axial velocity

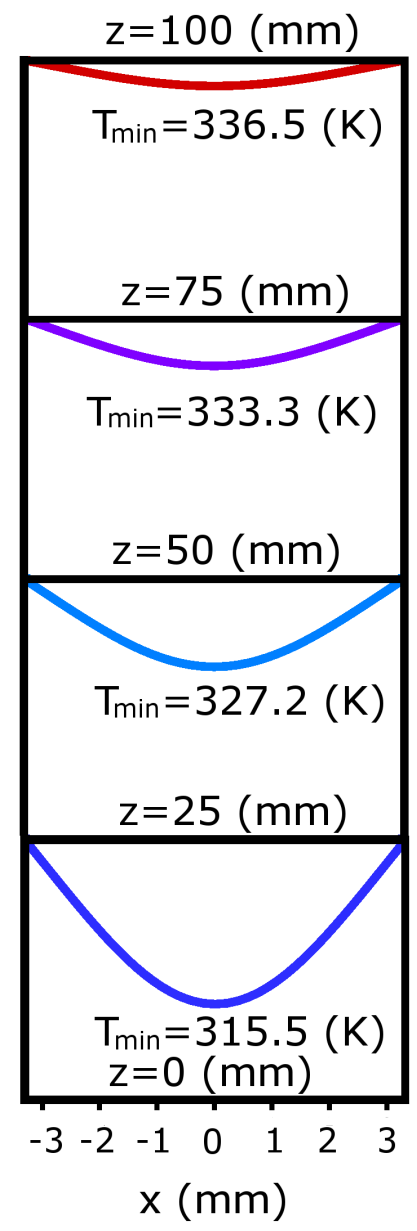

(b) temperature

Figure 7: Natural convection: axial velocity and temperature profiles at various heights for the optimal spacing, $D_{\text {opt }}=6.62 \mathrm{~mm}$. 


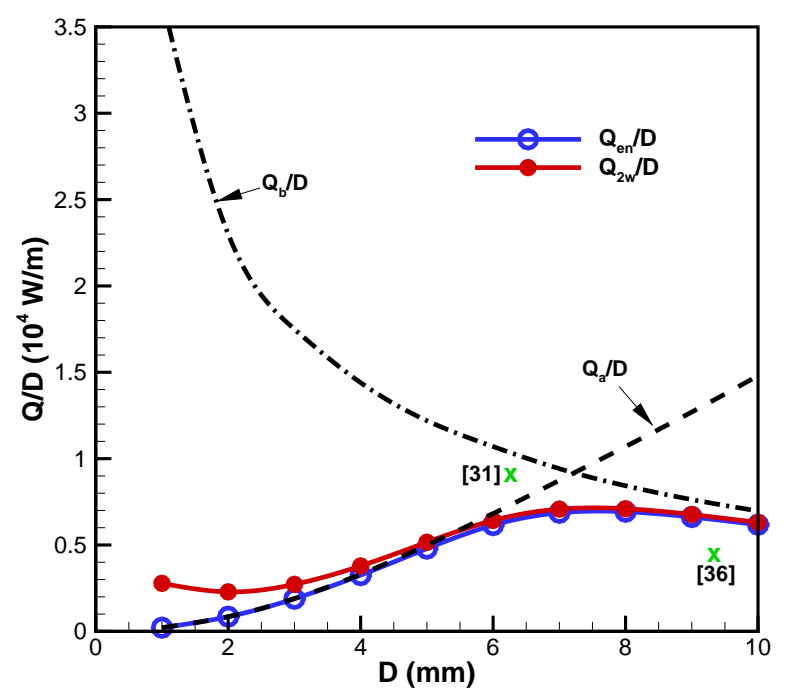

(a) $p_{s}=-0.1 P a$

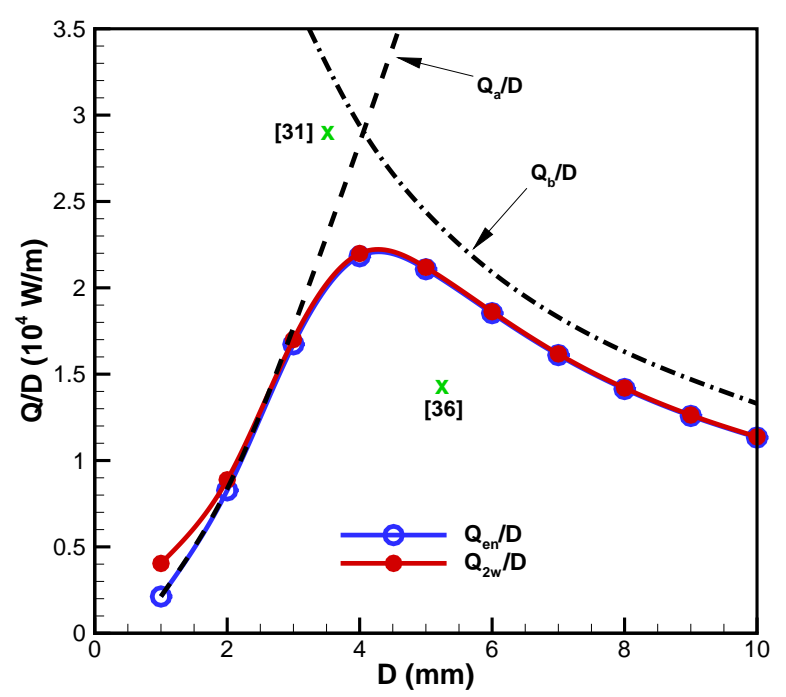

(b) $p_{s}=-1 P a$

Figure 8: Forced convection: variations of the ratios $Q / D$ with the plate spacing for $p_{s}=-0.1 P a$ and for $p_{s}=-1 P a\left(Q_{a}\right.$ and $Q_{b}$ are the asymptotic analytical solutions, $Q_{2 w}, Q_{e n}$ are given by Eqs. 13 and 14, respectively). The cross symbols are for the analytical solutions given by Eq. 37 [36] and Eq. 38 [31]. 


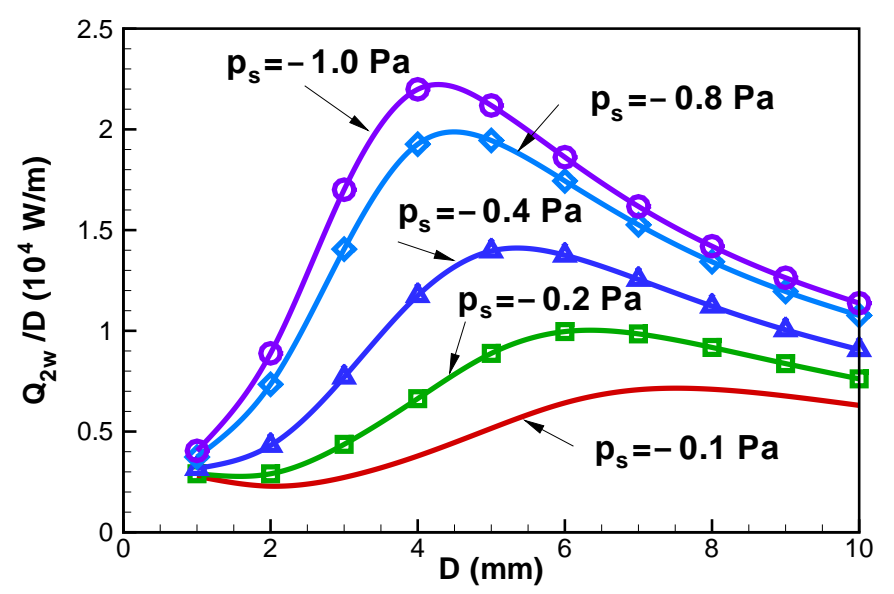

Figure 9: Forced convection: variations of the ratio $Q_{2 w} / D$ versus the plate spacing for various $p_{s}$.

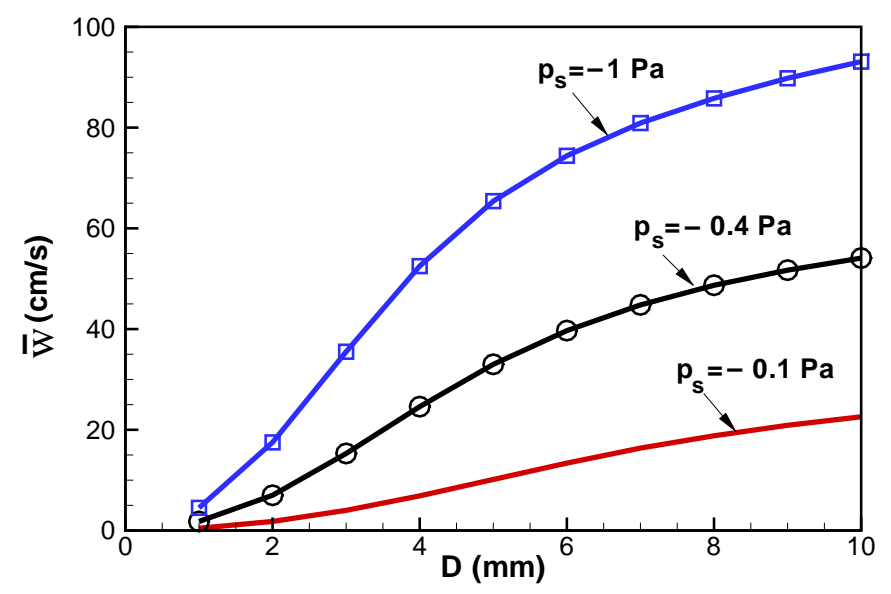

Figure 10: Forced convection: variations of the mean flow velocity versus the plate spacing for various $p_{s}$. 


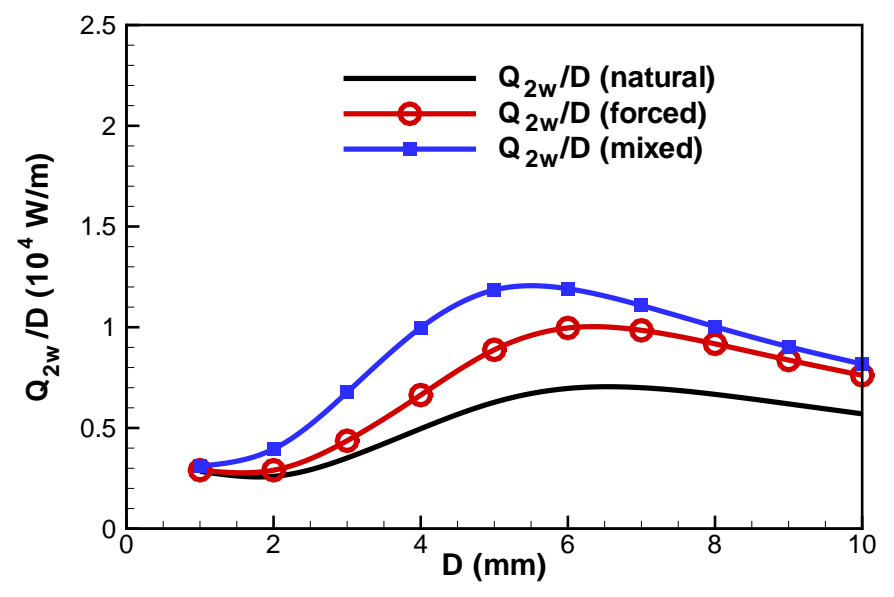

(a) $p_{s}=-0.2 P a$

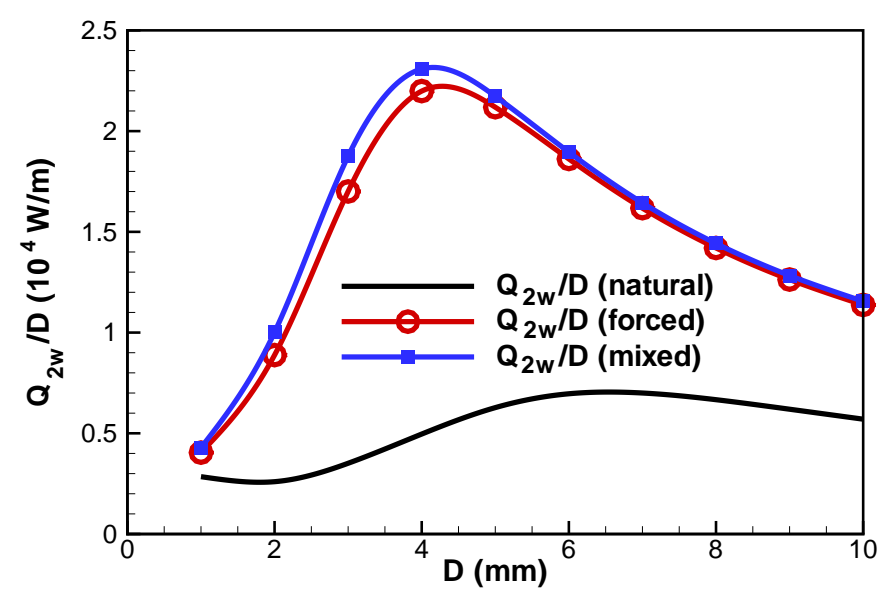

(b) $p_{s}=-1 P a$

Figure 11: Mixed convection : variations of the ratio $Q_{2 w} / D$ versus the plate spacing for forced and mixed convection. 


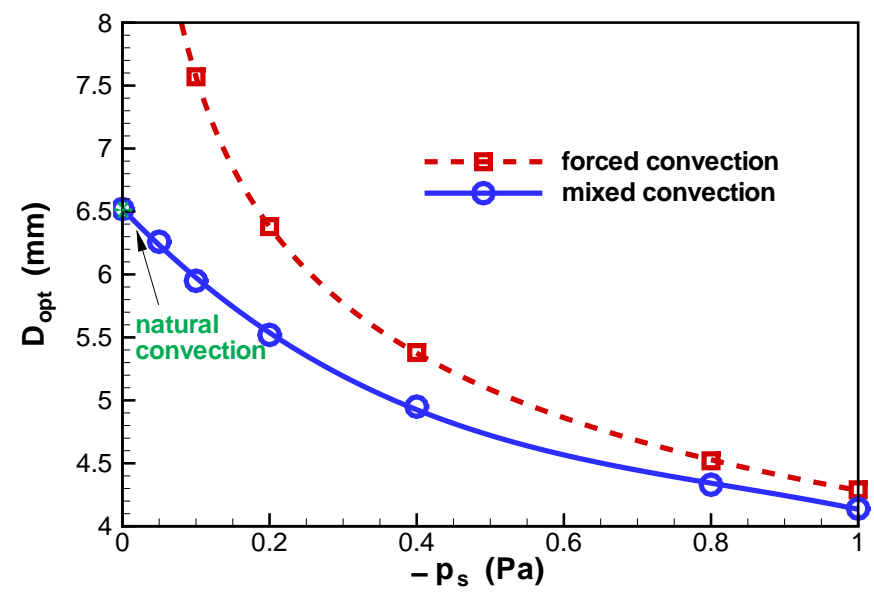

(a) $D_{\text {opt }}(\mathrm{mm})$

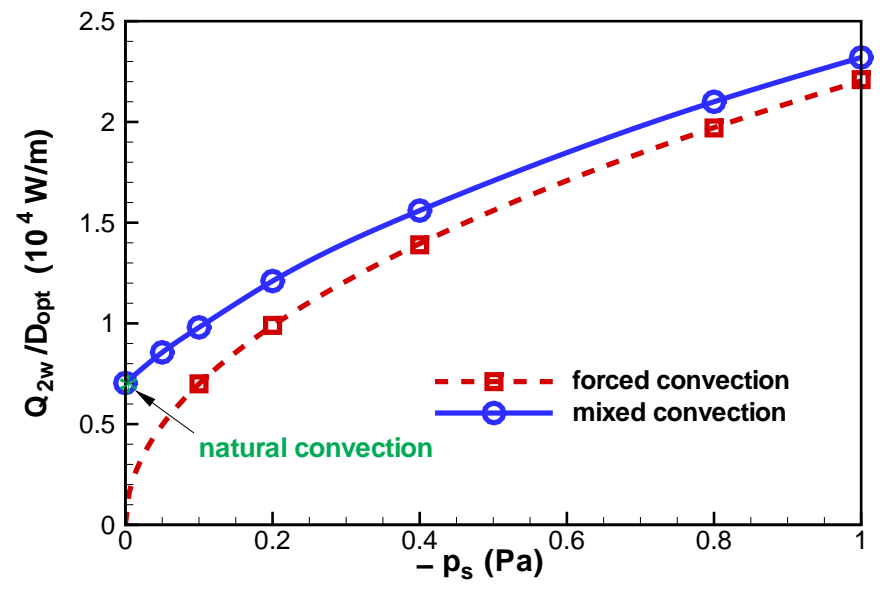

(b) $Q_{2 w} / D_{\text {opt }}(W / m)$

Figure 12: Mixed convection : variations of $D_{o p t}$ and $Q_{2 w} / D_{o p t}$ versus $p_{s}$ for forced and mixed convection. 


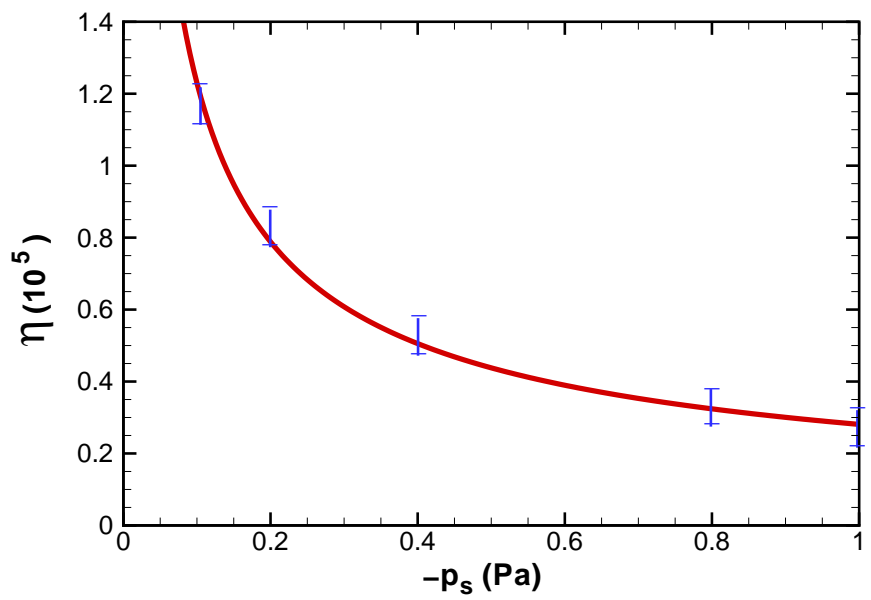

Figure 13: Variations of overall efficiency $\eta$ versus $p_{s}$ for mixed convection. 